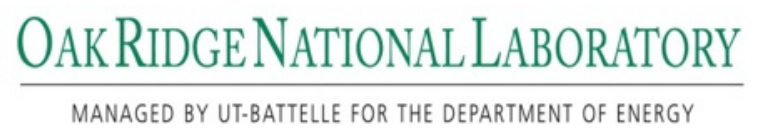

ORNL/ TM-2014/599

\title{
Friction Reduction through Surface Modification
}

(Texturing of Lubricated Sliding Surfaces)

Agreement Number: 23284

\author{
Peter J. Blau (retired) and Jun Qu \\ Oak Ridge National Laboratory \\ and \\ Stephen M. Hsu \\ George Washington University
}

\author{
Prepared by \\ Oak Ridge National Laboratory \\ Oak Ridge, TN 37831 \\ Managed by \\ UT-BATTELE, LLC \\ for the \\ U.S. Department of Energy \\ Under contract DE-AC05-00PR2225
}

$10 / 31 / 2014$

Approved for

Unlimited Distribution

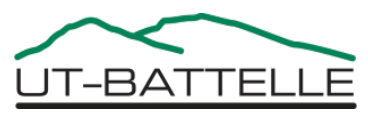




\section{DOCUMENT AVAILABILITY}

Reports produced after January 1, 1996, are generally available free via the U.S. Department of Energy (DOE) Information Bridge.

Web site http://www.osti.gov/bridge

Reports produced before January 1, 1996, may be purchased by members of the public from the following source.

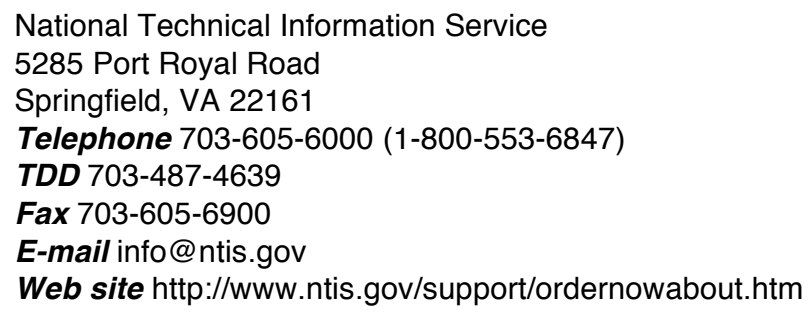

Reports are available to DOE employees, DOE contractors, Energy Technology Data Exchange (ETDE) representatives, and International Nuclear Information System (INIS) representatives from the following source.

Office of Scientific and Technical Information

P.O. Box 62

Oak Ridge, TN 37831

Telephone 865-576-8401

Fax 865-576-5728

E-mail reports@osti.gov

Web site http://www.osti.gov/contact.html

This report was prepared as an account of work sponsored by an agency of the United States Government. Neither the United States Government nor any agency thereof, nor any of their employees, makes any warranty, express or implied, or assumes any legal liability or responsibility for the accuracy, completeness, or usefulness of any information, apparatus, product, or process disclosed, or represents that its use would not infringe privately owned rights. Reference herein to any specific commercial product, process, or service by trade name, trademark, manufacturer, or otherwise, does not necessarily constitute or imply its endorsement, recommendation, or favoring by the United States Government or any agency thereof. The views and opinions of authors expressed herein do not necessarily state or reflect those of the United States Government or any agency thereof. 


\title{
Friction Reduction through Surface Modification
}

(Texturing of Lubricated Surfaces)

Prepared by

Peter J. Blau (retired), Jun Qu, Yan Zhou, Kevin M. Cooley, and Donald L. Erdman III Materials Science and Technology Division

Oak Ridge National Laboratory

and

Stephen M. Hsu

George Washington University

Prepared for

United States Department of Energy

Assistant Secretary for Energy Efficiency and Renewable Energy

Vehicle Technologies Office

\author{
Prepared by \\ OAK RIDGE NATIONAL LABORATORY \\ Oak Ridge, Tennessee 37831-6283 \\ managed by \\ UT-BATTELLE, LLC \\ for the \\ US DEPARTMENT OF ENERGY \\ under contract DE-AC05-00OR22725
}




\section{Foreword}

This final report covers work done at Oak Ridge National Laboratory and George Washington University with a goal of reducing the friction in moving parts of engines through the use of surface engineering methods that rely in part on the use of controlled patterns or surface textures, as they are sometimes called. Surface texturing approaches of various kinds have been used in the past for this purpose, but often by a trial and error, empirical approach. A prior report published in 2012 (Technical Report ORNL/TM - 2012/20 titled: "Use of Textured Surfaces to Mitigate Sliding Friction and Wear of Lubricated and Non-Lubricated Contacts") overviews past work and benchmarks the state-of-the-art. The new work described here consists of two approaches to friction control in lubricated engine parts: (1) controlled electrolytic etching of various combinations of shapes, and (2) compression texturing produced by indentation by a hard counterface. The overall purpose of this work was to improve the fuel efficiency of dieselpowered vehicles by employing patterns of micro-scale features and surface treatments to reduce the sliding friction between contacting surfaces in engines. Funding was provided by the U.S. Department of Energy (DOE), Office of Energy Efficiency and Renewable Energy, Office of Vehicle Technologies, under the Heavy Vehicle Propulsion Materials program, managed by Jerry Gibbs. No proprietary data or other commercially-sensitive information has been included. 


\section{CONTENTS}

\section{Executive Summary}

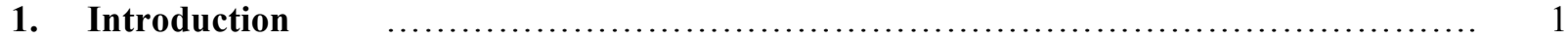

2. Compression Texturing (ORNL) $\quad \ldots \ldots \ldots \ldots \ldots \ldots \ldots \ldots \ldots \ldots \ldots \ldots$

2.1 Indentation by pyramidal shapes: method and friction results $\quad \ldots \ldots \ldots \ldots \ldots \ldots \ldots . \ldots$

2.2 Ball compression texturing: method and friction results $\quad \ldots \ldots \ldots \ldots \ldots \ldots \ldots \ldots \ldots \ldots \ldots$

2.3 Wire compression texturing: method and friction results $\quad \ldots \ldots \ldots \ldots \ldots \ldots \ldots \ldots \ldots \ldots$

3. Photolithographic Texturing (GWU) $\quad$....................... 17

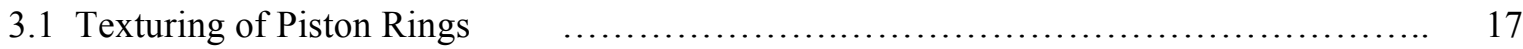

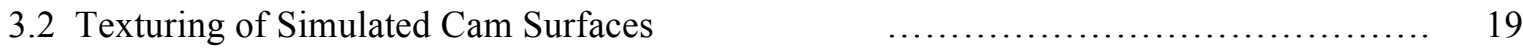

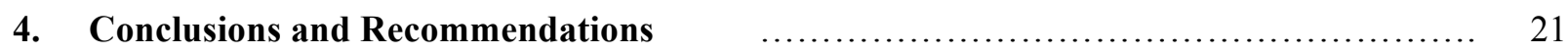

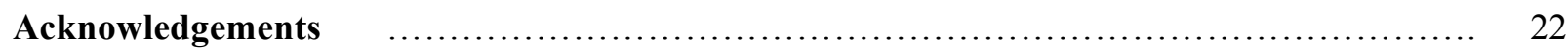

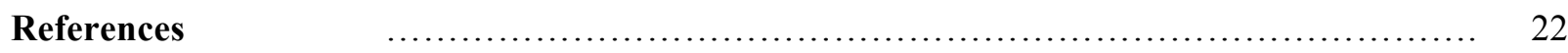

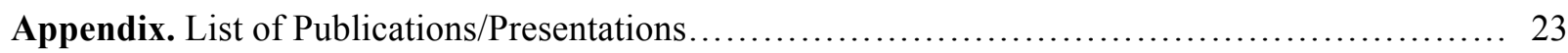




\section{EXECUTIVE SUMMARY}

If properly employed, the placement of three-dimensional feature patterns, referred to here as 'textures,' on relatively-moving, load-bearing surfaces can be beneficial to their friction and wear characteristics when used with lubricants. The concept is that in contrast to conformal surfaces without such features, textures affect lubricant flow and wear particle removal. In principle they can reduce friction by creating pressure spikes that push against the bearing load and in effect increase the lubricant film thickness and load-bearing characteristics. Textured surfaces generally show most pronounced effects when they are used in conformal or nearly conformal contacts, like that in face seals, because the confining geometry of the interface affects the flow of the lubricating fluid. Prior work also shows that excellent alignment of the mating bearing surfaces is key to realizing the benefits of textures and that not all textures can reduce friction. The application of this technology requires matching the design of the texture to the operating characteristics and lubricants used with the bearing component to which it is to be applied.

This final report summarizes three years of research on the texturing of load-bearing surfaces by two types of treatment methods: (a) mechanical compression-texturing (ORNL in-house research) and (b) micro-lithography (subcontract to George Washington University (GWU)). These complementary efforts helped to guide the approaches and experimental work done during the project. For example, observations by GWU that mixtures of features, like ovals and circular shapes, can extend the load range for beneficial effects on friction reduction. Thus, ORNL's work on wire mesh compression can be used to produce oval features joined by straight grooves, a more complex texture than the repeated simple shapes used by most other investigators.

The following mechanical compression texturing (CTx) methods were used by ORNL in this work:

- Computer-generated arrays of diamond-shaped micro-indentations

- Close-packed arrays of spherical dimples by compressing hardened precision bearing balls

○ Complex, multi-feature patterns produced by compression of hard wire woven screens

Load-displacement data were obtained during CTx experiments to correlate feature width, depth, and spacing with the deformational characteristics of the surfaces. Recognizing that most engine bearing surfaces are curved required that the techniques being developed be adaptable to concave or convex surfaces. A series of CTx experiments demonstrated that thin brass strips, mimicking the half-shell geometry of inserts for journal bearings in connecting rods, could be simultaneously formed into curves and also given complex surface textures in the same operation. Micro-lithographic methods developed at GWU demonstrated that texture patterns could be applied to the outside diameters of diesel engine piston ring segments.

The variety of texturing methods and patterns investigated in this work were friction-tested under lubricated conditions in several types of laboratory-scale devices. Some operated under reciprocating conditions, as would be experienced by a piston ring against a cylinder liner. Others operated in a continuous rotation mode, such as a journal bearing or cam lobe and follower. Together piston rings and engine bearings can account for over $70 \%$ of the total engine frictional losses, so the applicability of this work was extended by at least four several different friction test methods. One of the test methods was ASTM G181, designed for measuring the friction coefficient of piston rings against cylinder liners in hot lubricating oil, a method that, since its introduction, has been widely used by engine makers and lubricant formulators. Development of this standard was led by ORNL under prior funding by DOE.

Because the effectiveness of texturing is known to be affected by lubricant properties, several types of oils were included in this work. One type of lubricant, mainly used by GWU, was an oxidation-stabilized 
mineral oil without a full additive package. Two other types were (a) a conventional commercial diesel oil 15W40 Valvoline, and (b) a lower viscosity oil 0W30 being considered for future, low churning loss diesel and automotive engines. Since lowering the viscosity of the oil can beneficially reduce viscous drag losses, it can also reduce the lubricant film thickness, driving friction and wear up and requiring new anti-wear and friction modifiers in the additive package to compensate. Experiments with textures demonstrate that surface modification can in part help to compensate for these drawbacks of using low viscosity oil.

The primary conclusions and recommendations of this work are:

1) Surface texturing is not a universal cure for friction reduction, but can provide benefits in specific cases. Therefore, the application of interest and the lubricant must be amenable for texturing, including the proper alignment, temperature of operation, and regime of lubrication (boundary, mixed film, or hydrodynamic).

2) Effects of surface textures are highly dependent on the test configuration and parameters, and could be either beneficial (micro-elastohydrodynamic lift) or detrimental (higher effective roughness) on friction behavior.

3) Running-in (wear-in) of fresh surfaces can change the texturing pattern. Allowance must be provided so that the post running-in pattern will perform satisfactorily for a long period of time. This may involve providing a deeper initial texture to allow for wear-in, and/or application of a wear-resistant film that still retains the pattern but protects it.

4) ORNL's unique, variable load bearing test (VLBT) provided useful insights into the frictional variability and load dependence of candidate textured surfaces during running-in and steady state. It enables a better simulation of running conditions than the constant load and constant speed tests that populate the tribology literature.

5) Surface texturing combined with surface treatments like wear-resistant coatings or deposited lubricating films can extend the benefits over texturing alone.

6) The question as to whether to texture the rotating member or the fixed bearing surface is acknowledged as a factor in engine manufacture and design. This aspect is also recommended as a subject of further work.

7) A wide range of texturing options are available: lithographic, mechanical, laser, micro-machining, and more. Some are better suited for curved bearing surfaces than others. 


\subsection{Introduction}

Heavy vehicles, like Classes 7 and 8 trucks weighing over 26,000 lbs $(11,800 \mathrm{~kg})$ consume as much as 1.9 Million barrels of oil per day in the United States [1]. As Ref[1] also states:

“...the SuperTruck Program, a collaboration between DOE VTO (Vehicle Technologies Office) and industry partners in HDVs (heavy duty vehicles), takes a holistic approach to increasing freight efficiency through "clean sheet" design of the Class 8 vehicle resulting in improved aerodynamics, engine and powertrain efficiencies, and reduced weight of the tractor and trailer."

There is considerable room for improvement in heavy vehicle fuel economy, since studies have shown that heavy trucks typically travel only 3-7 miles per gallon of diesel fuel consumed, depending on vehicle configuration and speed [2]. In addition to weight reduction, improved tire design, and aerodynamic optimization, reduced engine and drivetrain friction can also improve fuel economy. Therefore the Department of Energy has invested in tribology (friction, wear, and lubrication) research to improve engine efficiency.

Friction control and reduction can be achieved in a number of ways, depending on the application involved:

- Improved vehicle component designs to reduce severity of surface contact

- Improved lubricant formulations for wear and friction reduction

- Lower viscosity lubricants to reduce churning losses

- Additives to enhance fuel lubricity

- Improved bearing surface materials and low-friction coatings

- Optimized surface finishes, running-in, and manufacturing practices

- Textured surfaces for lubricant flow and debris control

This project focuses on engine friction reduction using the final approach on the list. In materials science, the term 'texture' is used to refer to the preferred orientation of crystalline grains within a material. In machining science and surface metrology it refers to the roughness, waviness, and lay (directionality) of surface features. In tribology, the current context, the term texture will refer to the form, dimensions, and patterning of a surface as well as the associated effects produced on the underlying material. Some textures arise by design, but some, like processing artifacts (e.g., upset ridges, micro-cracks, subsurface work-hardened areas), result from machining and finishing.

In tribology, the four basic functions of intentional texturing are:

(i) to alter the flow and film thickness of lubricating fluids locally and across the contact region,

(ii) to supply lubricant to a surface

(ii) to trap debris that would otherwise become embedded or abrade the surfaces, and

(iii) to alter the bearing pressure distribution.

Engineers have long applied geometric features to lubricated solid surfaces in order to control friction and wear (i.e., even for centuries, if the definition of 'engineered surfaces' is extended to include millstones and the like). Owing to advances in materials and processing, the variety of the patterns and the methods used to produce them have evolved greatly. Likewise, computer-based models to portray the effects of textured surfaces on contact stresses, lubricant film thickness, and friction have become more rigorous and physically realistic. 
It is well-known that friction reduction of moving parts of internal combustion engines improves efficiency and fuel economy. Therefore, it is important to consider all friction control options when designing internal rubbing surfaces. These include improved lubricants, improved design of mating parts, use of coatings and surface treatments, and the texturing of surfaces. The control of surface finishes and machining processes like plateau-honing have long been used to improve bearing performance, but the present project emphasizes approaches that go beyond the considerations of roughness, waviness, and lay that are associated with traditional machining.

Various terms have been used to describe the intentional synthesis of periodic geometric features on a bearing surface. These include textured surfaces, patterned surfaces, and modulated surfaces. Such surfaces can be designed with an endless variety of features, as will be described. Some are round, some are sharp, some are shallow, and some are relatively deep. Some features are discontinuous, like dimples, pores, and separated shapes. Others are continuous, like grooves and cross-hatched patterns whose valleys and peaks run completely across the contact surface. Another consideration is whether one or both mating surfaces are patterned. It may be neither necessary nor desirable to pattern both counterfaces.

As will be discussed subsequently, geometric surface texturing is only one aspect of surface engineering. Potentially, microstructural design, coatings, or compositional surface engineering can be combined with geometric texturing to provide further friction and wear benefits.

As mentioned above, textured surfaces have geometric and microstructural attributes. These attributes are generally larger in scale than the surface finish of a typical bearing or gear (typically from $0.025-0.3 \mu \mathrm{m}$ in arithmetic roughness), but in special cases they can be only a few $\mathrm{nm}$ in size. Several attributes of textured surfaces are depicted in Figure 1 (from [3]). They can be categorized as follows:

- Individual feature shape(s), including the depth profiles of the cavities

- Individual feature dimensions

- Asymmetry of patterns and features (aspect ratio)

- Orientation of the features relative to the lubricant supply

- Orientation of the features relative to the direction of relative motion with the counterface

- Whether one or both mating surfaces are textured

- Feature spacing relative to adjacent features

- Fraction or percentage of the apparent contact area occupied by features

- Mixtures of feature shapes versus similar shapes throughout the pattern

- Artifacts such as edge ridges or subsurface 'affected zones'

As exemplified by Figure 1, an enormous number of possibilities exist to optimize texture-based surface engineering of tribosystems. There is a nearly endless set of combinations of feature shapes, sizes, and orientations. Furthermore, one should distinguish between intentional geometric features and artifacts that result from the texturing process, such as 'splash zone' ridges around laser produced dimples or surrounding ridges of material due to indentation or micromachining methods.

The literature [3] reveals several variables and surface characteristics which seem to have the most effects on the effectiveness of texturing on friction modification. In addition to the items listed above, the following characteristics were of particular interest in this work:

- Feature sizes, shape(s), and depth relative to the initial surface finish and lubricating film thickness under operation

- Density of features relative to the total area of bearing contact (expressed as a \% of area)

- The wear resistance of the bearing surface as it affects the preservation of texture patterns 
- The running-in characteristics of freshly-mated surfaces, as it affects longer term performance

- The role of the lubricant viscosity on texture functionality

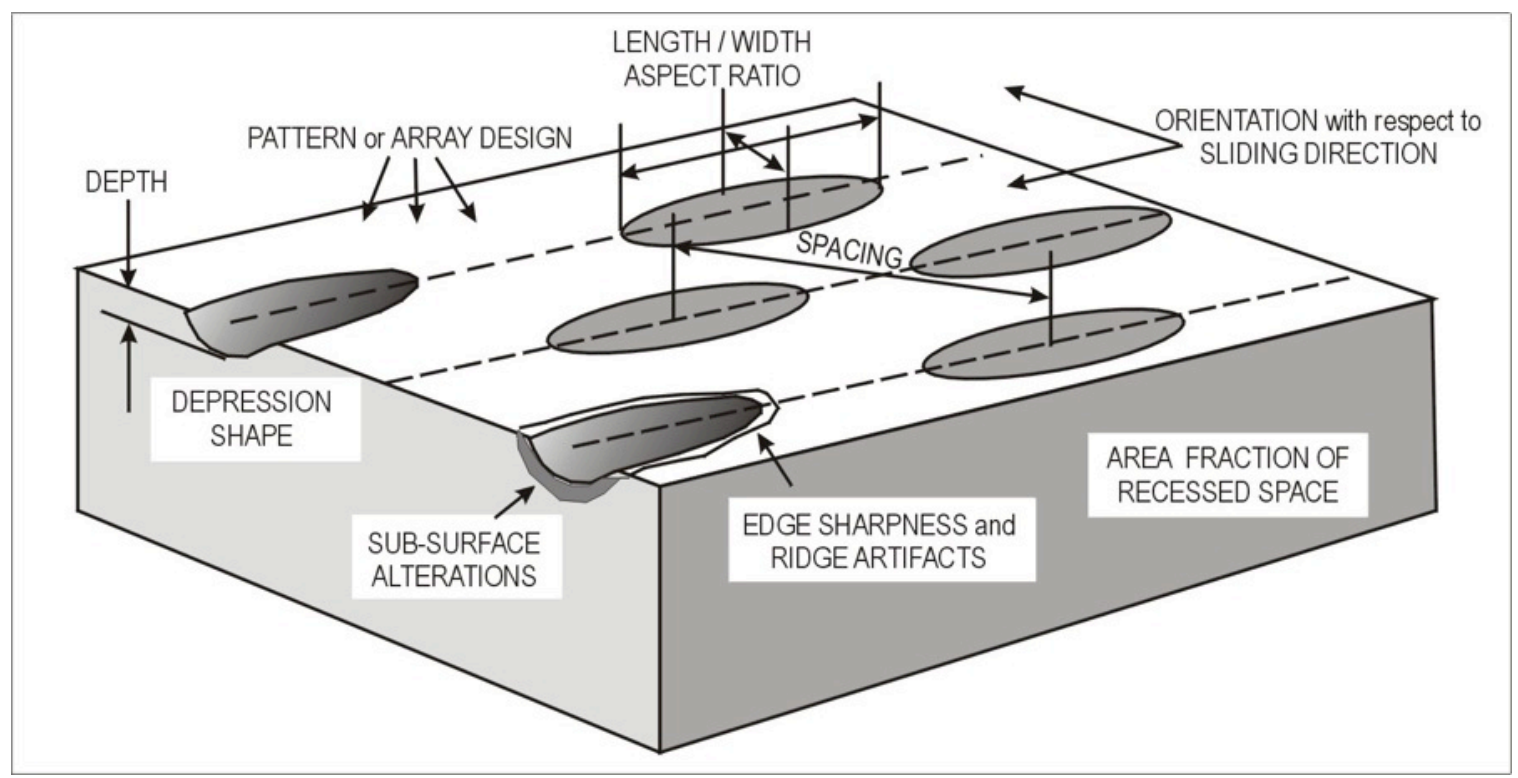

Figure 1. Some attributes of textured surfaces. (Source: Ref. [3]).

Texturing is but one of several tools in the portfolio of surface modification methods for friction and wear control. Others include compositional modification by various methods (diffusion treatments, ion implantation, etc.), use of thin coatings (hard films, soft solid lubricating films, low friction diamond films, etc.), and mechanical treatments (e.g. shot peening). These additional tool can be used with texturing to produce what will be called an 'integrated surface modification approach.

The optimum ratio of the dimple depth over diameter was found to be between 0.1 to 0.18 [4]. The density of features has a profound influence on the friction reduction. Using stainless steel surfaces and circle-shaped features, it was presented that a $20-30 \%$ surface coverage enhanced the friction performance [5]. For surfaces of circular-pocket features, the oil film of maximum thickness formed when the surface coverage was $11 \%$ [6]. Wakuda et al. [7] performed characterizations on the surfaces of micro-dimples and determined that the lower densities ( 7.5 and 15\%) outperformed the higher density (30\%), probably due to the increased pressure from the decreased contact area overwhelms the benefits from local pressurization of oil film. Pettersson and Jacobson [8] have shown that the smaller sizes performed better than the bigger ones: 5 and $20 \mu \mathrm{m}$ grooves and $5 \mu \mathrm{m}$ squares performed better than the $50 \mu \mathrm{m}$ grooves and $20 \mu \mathrm{m}$ squares. But the coated surfaces do not always provide benefits on the friction when combined with the textures. The shape edges of the textures scrape off the transferred self-lubricating layer from the DLC and caused a reduction of the effectiveness of the textures.

In this project, two principle types of texturing methods were examined: micro-lithography (micro-etched features), and compression texturing (mechanically impressed patterns. The former approach was taken by Dr. S. M. Hsu at George Washington University under a subcontract to ORNL, and the latter was taken in-house at ORNL. Each method, described in separate sections below offers advantages and disadvantages. 
An analysis of the contributions to engine friction losses, described in the classic text by Taylor [9] indicate that together, the piston-ring/liner interface and the engine bearings together can account for up to $70 \%$ of the total losses. Therefore, three engine components were chosen to be focus of this work: (i) the interface between the piston ring and cylinder liner, (ii) the cam-lobe lifter interface, and (iii) the connecting rod large-end bearing. The former represents reciprocating motion and the latter two, unidirectional sliding. Therefore, the effects of integrated surface modification would likely affect performance differently in such cases. Test methods employed in this project to validate the microlithographic and compression texturing approaches also involve the two different types of sliding motion to ensure that the results of the work are widely applicable.

\subsection{Compression Texturing (ORNL)}

The primary material selected for compression texturing work was a typical bearing bronze (CDA 932). A very common bearing bronze used in engine components, its nominal composition in wt $\%$ is: $83 \mathrm{Cu}, 3$ $\mathrm{Zn}, 6.7 \mathrm{Sn}, 7 \mathrm{~Pb}$ with minor permissible amounts of $\mathrm{Sb}, \mathrm{S}, \mathrm{Si}, \mathrm{Fe}$, and $\mathrm{Al}$. In some experiments, described latter in this section, alloy CDA 260 (cartridge brass, $70 \mathrm{Cu}, 30 \mathrm{Zn}$ ) was also used because CDA 932 is normally used in the as-cast condition and was not available in strip form for shape-forming experiments.

Compression texturing (abbreviated here as CTx) uses a mechanically-applied force on a hard indenting body to produce a pattern or texture on a softer bearing surface. In the current work, three different methods were used to explore the potential benefits of CTx. These are discussed in the following subsections:

2.1 Indentation by pyramidal shapes: method and friction studies

2.2 Ball compression texturing: method and friction studies

2.3 Wire compression texturing: method and friction studies

\subsection{Indentation by Pyramidal Shapes: Method and Friction Results}

Arrays of pyramidal shapes were produced using an automated microindentation hardness tester in which the positions of indentations can be programmed. On each test specimen, a flat smoothly polished test coupon, 3,675 individual diamond Vickers indenter micro-indentations were placed in a $5 \times 8 \mathrm{~mm}$ array, spaced $150 \mu \mathrm{m}$ apart horizontally, and $75 \mu \mathrm{m}$ between half-spaced, off-set rows (see the optical photomicrograph in Fig. 2).

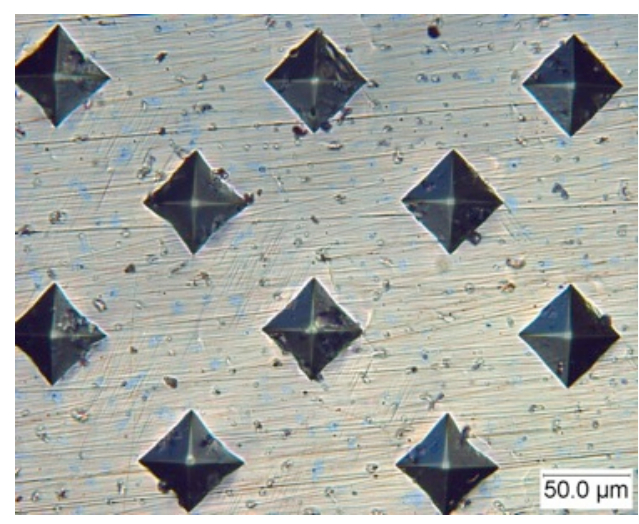

Figure 2. Array of Vickers microindentation impressions placed $0.150 \mathrm{~mm}$ apart to form a textured surface on bearing bronze (as-indented). 
With an average impression diagonal length of $58.5 \mu \mathrm{m}$ at a load of $200 \mathrm{~g}-\mathrm{f}$ (corresponding to an average $\mathrm{HV}$ of $108.3 \mathrm{~kg} / \mathrm{mm}^{2}$ ), the area fraction of indentations was calculated to be $15.2 \%$. Using a quantitative image analysis system and optical microscope, digital images were obtained and analyzed with a $20 \mathrm{X}$ objective lens. The measured area fraction of indentations was $15.2 \%$, precisely as predicted from hardness theory. Using a vertical scanning interferometer (VSI) (Wyko 9100, Bruker Instruments), the upward surface displacement surrounding the indentations was measured. Figure 3 shows a 3D vertical scanning interferometric image (VSI) of two impressions. Color-coded by feature height, it shows that indentation texturing of a surface can raise hills of material adjacent to it. In this case, the upset areas required further polishing to produce a flat surface with an array of negative features.

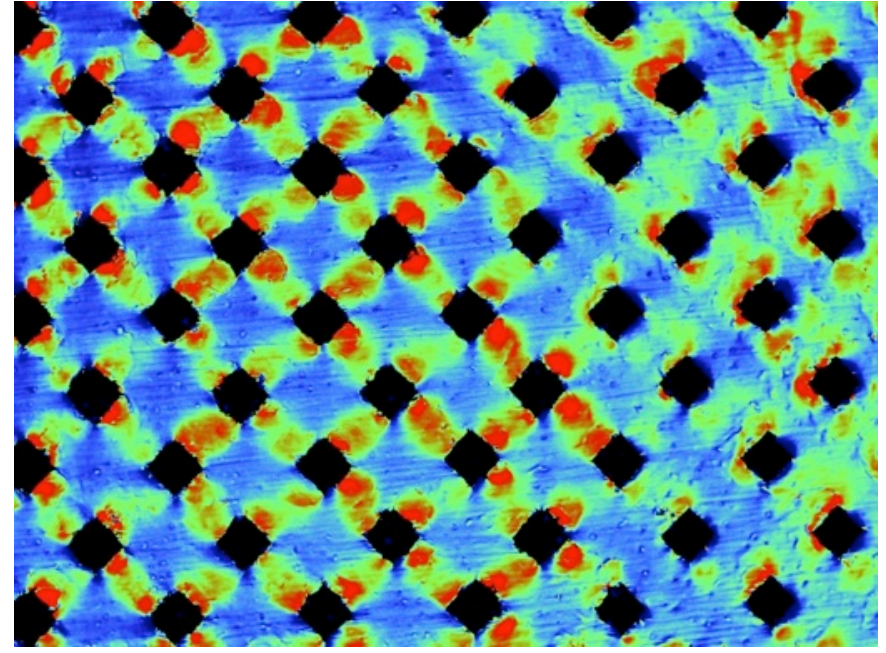

(a)

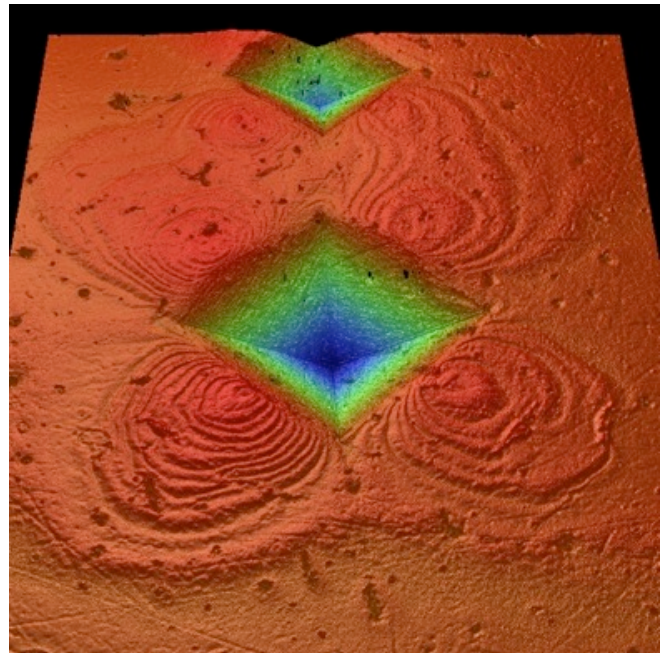

(b)

Figure 3. VSI 3D topographic image of Vickers impressions in bronze showing raised ridges due to plastic deformation and material displacement. (a) area of indentations, (b) detail of deformation near individual impressions (200 g-f load, bottom and $100 \mathrm{~g}-\mathrm{f}$ load, top).

Data in Figure 4 summarize the height of the ridges formed around the impressions and their total depths. The height of the plastically deformed, raised edge on indentations (h) tends toward about $14 \%$ of the depth of the impression (z), and is nearly independent of the applied load, if the load exceeds $\sim 100$ gramsforce. Note that the preliminary friction experiments to validate this approach were conducted on flat test pieces that use 200 gr-f to make indentations. Therefore, the average depth of the impressions was about 8 $\mu \mathrm{m}$ and the surrounding ridge height was slightly more than $1 \mu \mathrm{m}$. 


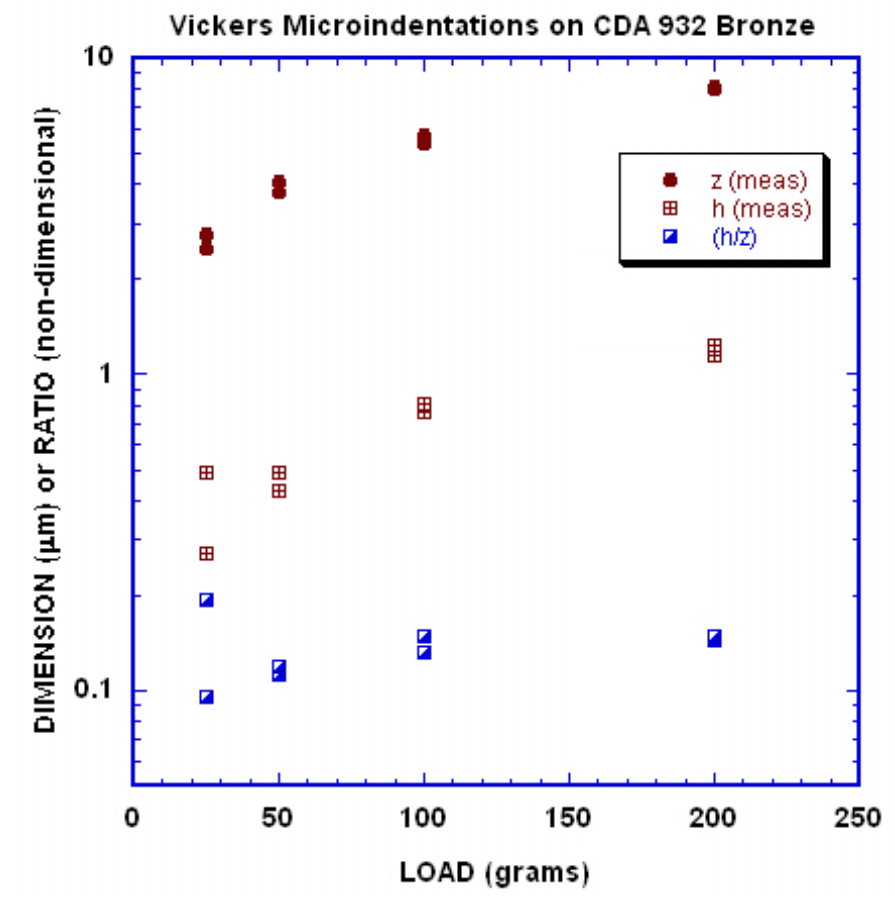

Figure 4. Comparison of the depth of the indentations $(\mathrm{z})$ in bronze to the height of the ridge (h) surrounding the impression (two of the impressions are shown in Figure 2). The $(\mathrm{h} / \mathrm{z})$ ratio is relatively constant at the higher loads.

Friction tests on indented arrays. Friction experiments were conducted on these surfaces using a reciprocating sliding, ball-on-flat configuration. Fixed AISI 52100 bearing steel balls were used as sliders, oscillating at $10 \mathrm{~Hz}$, with a stroke length of $10 \mathrm{~mm}$, at loads between 25 and $150 \mathrm{~N}$ in $15 \mathrm{~W} 40$ diesel oil (Valvoline Blue ${ }^{\mathrm{TM}}$ ). Side-by-side wear tracks were placed on and adjacent to the textured area on the bronze specimens. Figure 5 (a) shows several wear tracks on indentation textured bronze. While these were generated in a ball-on-flat test at higher loads, which characteristically has a high initial contact stress ('point contact'), it illustrates the concern that patterns can be worn down and loose their effectiveness. Results from early tests (e.g., Fig. 5(b), produced only barely detectable improvements.

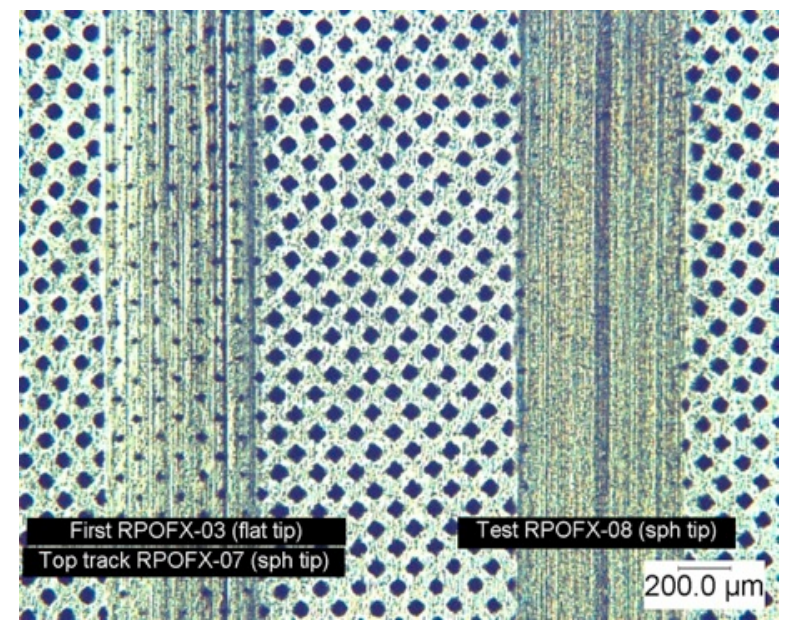

(a)

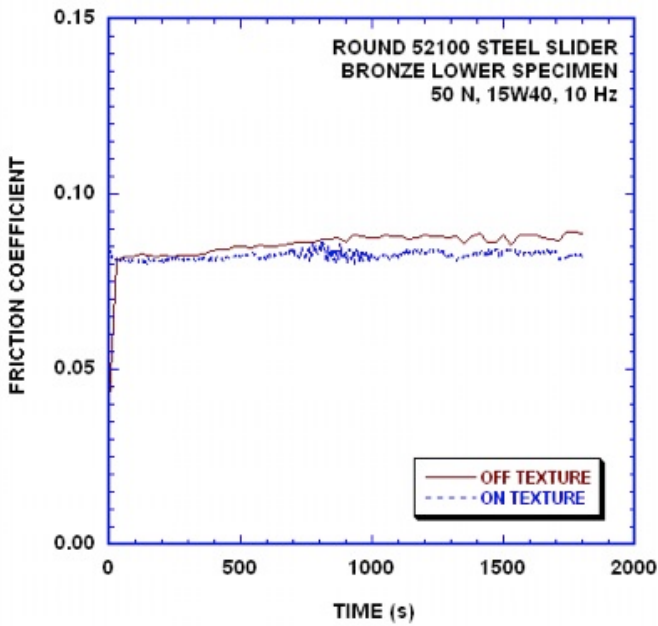

(b)

Figure 5. Oscillating ball on flat wear tests showing several tracks with partly or fully obliterated patterns (a), and comparison of tests on an off the patterned area (b) at a lower load that did not wear down the patterns as much. 
In conclusion, experiments with lubricated, concentrated contacts (ball-on-flat) on indentation arrays produced less than encouraging results. Also, in light of the physical difficulty of placing indentations on curved surfaces, as in production bearing inserts or piston rings, it was decided to abandon indentation array texturing and focus on alternative methods.

\subsection{Ball Compression Texturing: Method and Friction Results}

A special fixture was designed to hold an array of high-precision bearing steel balls in a servo-hydraulic compression testing machine in a mechanical testing facility at ORNL. Ball compression texturing (BCTx) was done using precision bearing balls $1.000 \mathrm{~mm}$ in diameter. A set of loose balls prior to indentation is shown in Fig. 6(a). They naturally form a hexagonal close-packed array. Figure 6(b) shows the dimples produced by indenting a CDA 932 coupon by the balls shown in Fig. 6(a). Using vertical scanning interferometry, dimple depths, spacings, and ridge heights were measured (see Fig. 7).

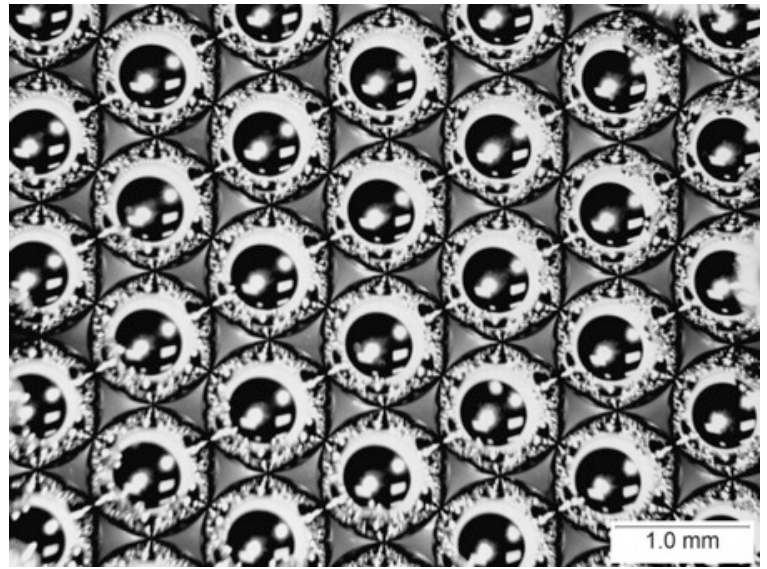

(a)

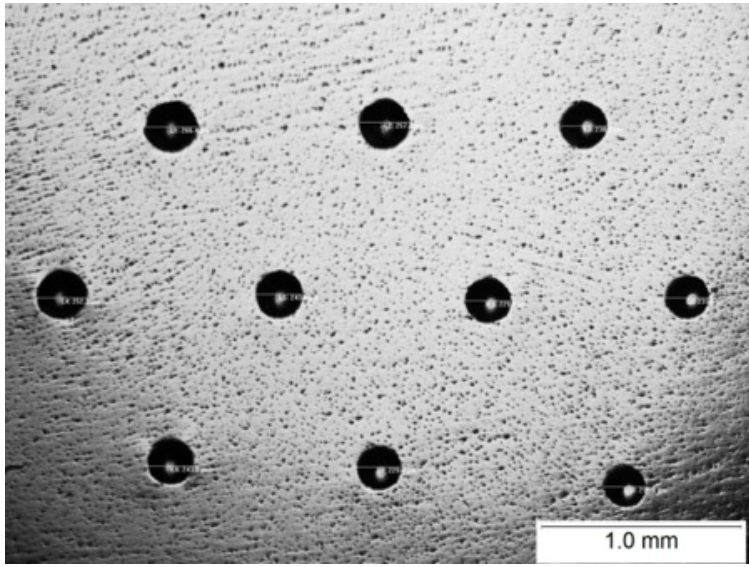

(b)

Figure 6. Compression texturing using loose bearing balls. (a) precision $1.00 \mathrm{~mm}$ diameter bearing balls, (b) impressions in CDA 932 bronze produced by ball indentation of the array in (a). While the pattern is relatively regular, the areal density of dimples is small.

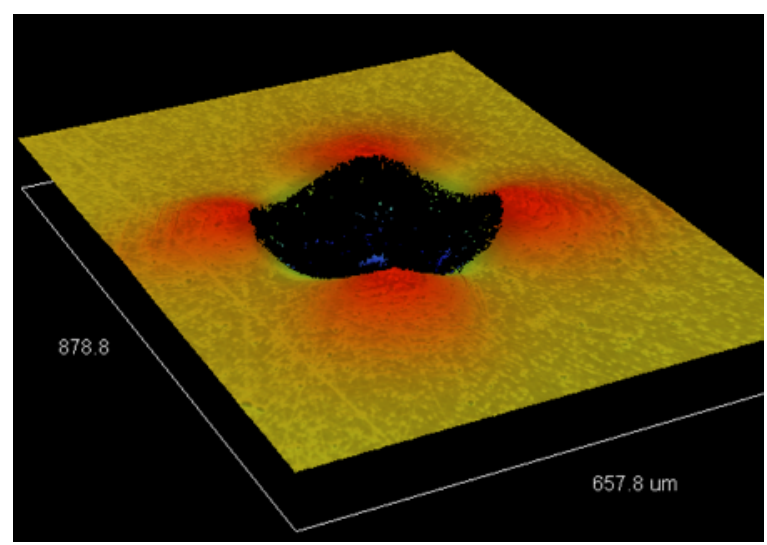

Figure 7. Topographic 3D image of a ball indentation in bronze alloy CDA 932. Raised areas resulted from nonuniform deformation. The average height of such raised rims was $1.33 \mu \mathrm{m}$ (std dev. $=0.55 \mu \mathrm{m}) ; 7$ measurements. 
A series of VLBT unidirectional sliding experiments in 15W40 fully formulated oil was conducted on BCTx arrays. The wear scar was placed along a row of dimples (see Fig. 8). Assuming that the wear scar width and length between dimples is that shown in the figure, it was possible to calculate the effective area percentage of dimples in the wearing contact area. Given a dimple spacing of $0.986 \mathrm{~mm}$, dimple diameter of $0.264 \mathrm{~mm}$, and wear scar width of $0.491 \mathrm{~mm}$, the area percent of dimples was only $11.3 \%$.

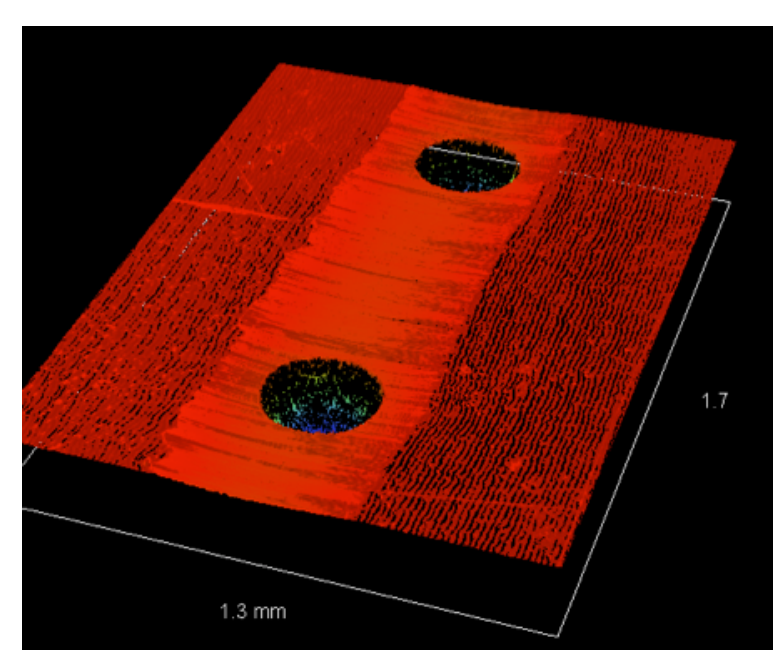

Figure 8. Wear scar from a sliding friction experiment of a cylinder on a flat specimen of BCTx bronze. The specimens were positioned so that the wear scar lay directly along a row of dimples.

In conclusion, dimple arrays produced by BCTx proved to be impractical for several reasons.

1) While regular arrays could be produced, the physical process of adjusting the balls was difficult and not well suited for automation.

2) The need to apply high loads to obtain sufficient dimple density to product and effect on lubrication was impractical and limited the bearing to surface material to relatively soft alloys.

3) The higher CTx load, the more raised rims were produced around the dimples. To obtain both a high density and deep dimples, the rims became more of a problem because they necessitated repolishing the surfaces to remove these rims (adding another manufacturing step and more cost).

\subsection{Wire compression texturing: method and friction studies}

The methods described in 2.1 and 2.2, while informative as basic studies of mechanical texturing, were not seen to be practical for extension to curved surfaces. Furthermore, as work at GWU with mixed shapes showed, it was desirable to produce more complex patterns on surfaces in order to enhance their friction-reducing effects. Therefore, in year 2 of this project, the approach was broadened to enable complex pattern generation by a process we call wire compression texturing. Wire compression texturing (WCTx) utilizes a servo-hydraulic compression testing machine to impress a hard wire mesh into a surface to create the pattern.

Three types of specimen geometries were prepared for friction studies using the VLBT machine. The first series of experiments used rectangular blocks (25.4 mm square x $6.35 \mathrm{~mm}$ thick) CDA 932 bronze as the 
test piece. A second set of experiments employed curved strips of CDA 260 brass. The bronze was not available in strip stock (normally it is only provided as cast or and rolled plate), so brass was used to demonstrate the application of CTx pressing to form and texture curved surfaces. A third set of experiments used CDA 932 bronze specimens into which cylindrical arcs had been machined to better mimic a journal bearing bore. Initially, however, baseline tests were performed on non-textured, but polished bronze surfaces.

\section{Baseline friction tests on polished surfaces}

The effects of oil viscosity on friction coefficient during running-in were first investigated using the VLBT at constant load. As usual, an AISI 8620 steel cylinder was used as the rotating specimen and a flat, 240 grit-finished CDA 932 bronze coupon was used as the stationary counterface. The applied loads were 62 and $102 \mathrm{~N}$, sliding speed was $0.1 \mathrm{~m} / \mathrm{s}$, and the test length was $1000 \mathrm{~s}$. The friction of two oils was compared, a standard Valvoline Blue ${ }^{\mathrm{TM}} 15 \mathrm{~W} 40$ diesel oil and a 0W30, low viscosity oil. The results in Figure 9 show that the low viscosity oil produced higher friction. This was expected from the MartensStribeck relationship in which the film thickness of the lower viscosity oil would be insufficient to avoid solid contact. The challenge for this project was to compensate for such reduced performance by applying CTx patterns.

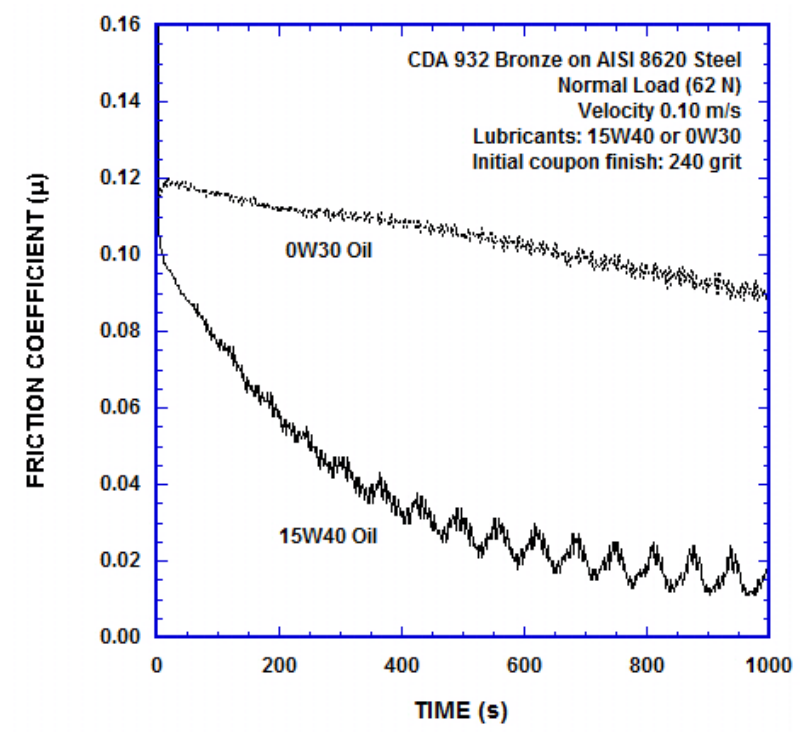

(a)

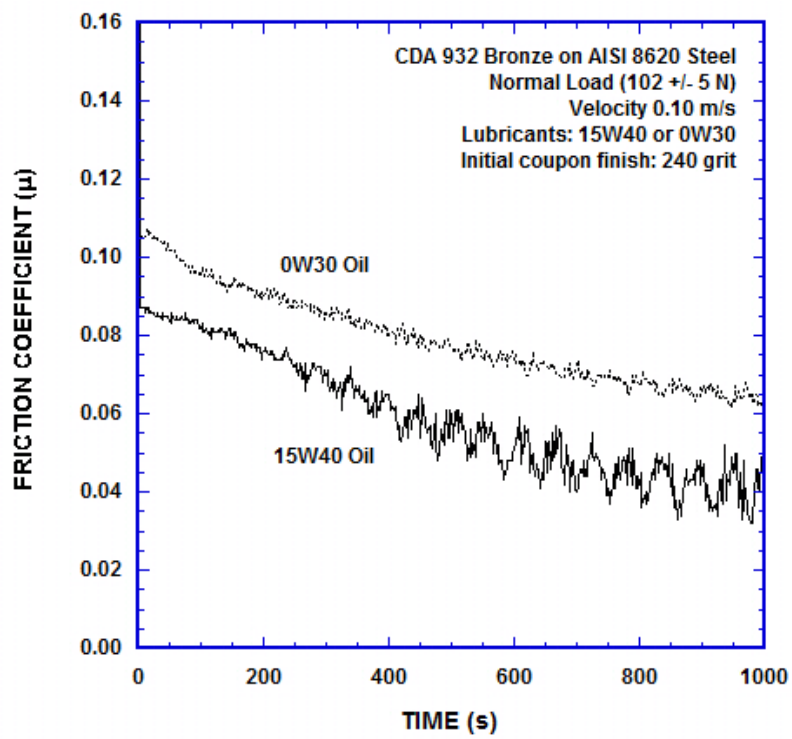

(b)

Figure 9. Effects of lubricant type on friction under two different normal loads. (a) $62 \mathrm{~N}$ and (b) $102 \mathrm{~N}$. The effects of oil viscosity were more evident at lower load.

In contrast to Figure 9, Figure 10 shows the response of the low viscosity oil to a spectrum of loads, as would be typical of an operating engine. The friction coefficient versus time trace in Figure 10 (a) clearly shows the repeated shapes for individual step loading cycles because the friction coefficient changed as the load changed. If there were no effect of load on friction, as in a simple Coulomb's friction law approach, then the plot would be horizontal.

Figure 10(b) extracts the friction coefficient versus load from the series of loading steps that are shown in Figure 10(a). The data approximately fit a linear relationship. Having established baseline data on the frictional effects of lubricant viscosity with variable loading behavior of non-textured surfaces, further 
studies will investigate that behavior with textures produced by a method we call compression texturing (CTx).

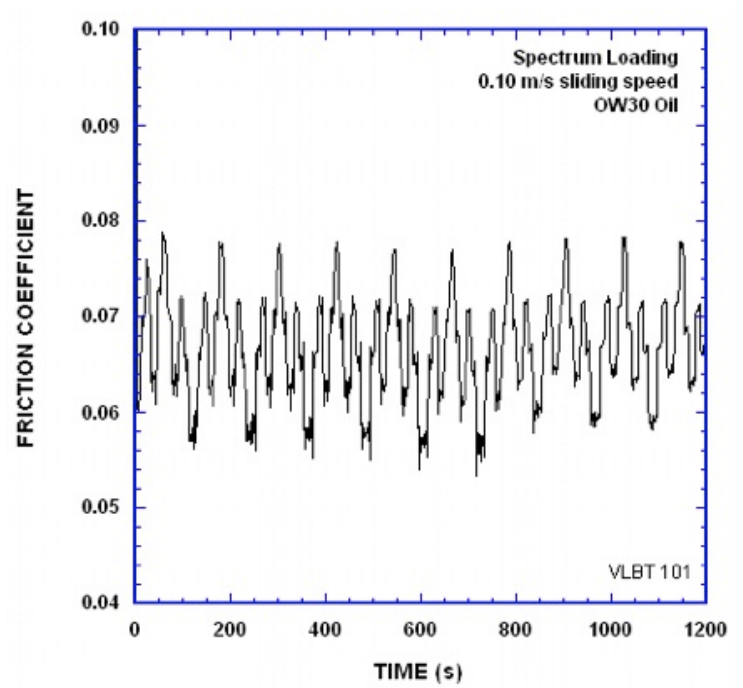

(a)

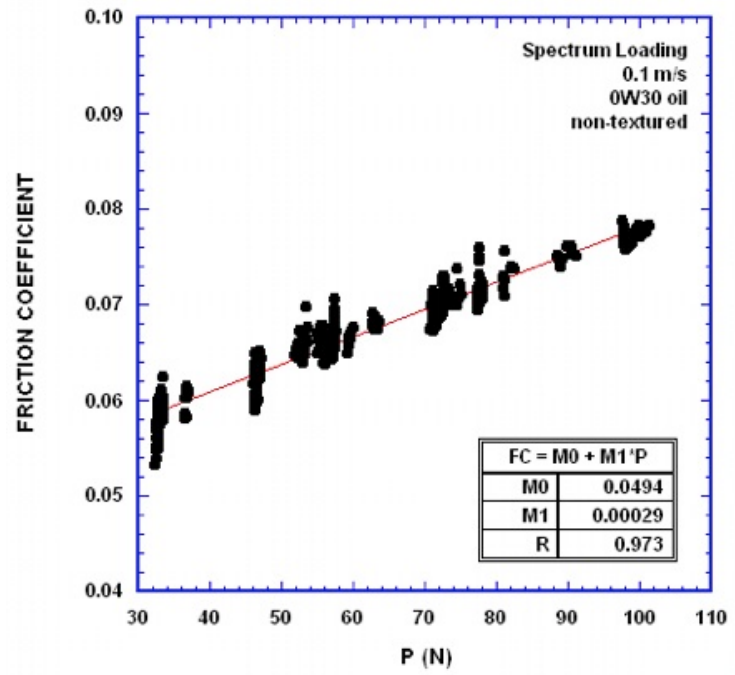

(b)

Figure 10. Effect of spectrum loading on frictional behavior in $0 \mathrm{~W} 30$ oil. (a) Shapes of the friction coefficient trace clearly show the ten loading cycles used to simulate a connecting rod bearing. (b) Data from (a) re-plotted as the average friction coefficient corresponding to each normal force step. Friction coefficient varies with applied load.

As mentioned, two geometries of WCTx geometries were used in this work. One was a planar substrate and the other a thin, bendable strip or a solid block into which a cylindrical groove was machined. Wire meshes were pressed into test couple surfaces using the geometries depicted in Figures 11 (a) and (b). High hardness tungsten wire mesh in four coarseness grades $(20 \times 20$ per inch -0.005 " wire dia., $50 \times 50$ per inch -0.002 " wire dia., $100 \times 100$ per inch -0.001 " wire dia., and $140 \times 140$ per inch -0.0007 " wire dia.) were obtained from a specialty wire mesh manufacturer (Unique Wire Weaving Co., Inc, New Jersey). Unused screens and the textures produced are shown in Figures 12. The mesh and wire sizes were chosen such that the features after impressing were typical in dimension to those from laser dimpling, GWU micro-lithographic texturing, and other dimpled surfaces reported in the literature. The standard over-under alternating weave is a standard pattern that will produce ellipses with long axes at 0 and 90 degrees connected by cylindrical grooves. For CTx-100, in order to increase the surface coverage of the textures, mesh was pressed twice at 90 and 45 degrees. For CTx-140, three compressions were applied: 90, 45, and 0 degrees. During such experiments, the load and displacement of the ram was monitored so that the effects of applied load and pressing conditions could be correlated with the pattern depth and feature dimensions. 


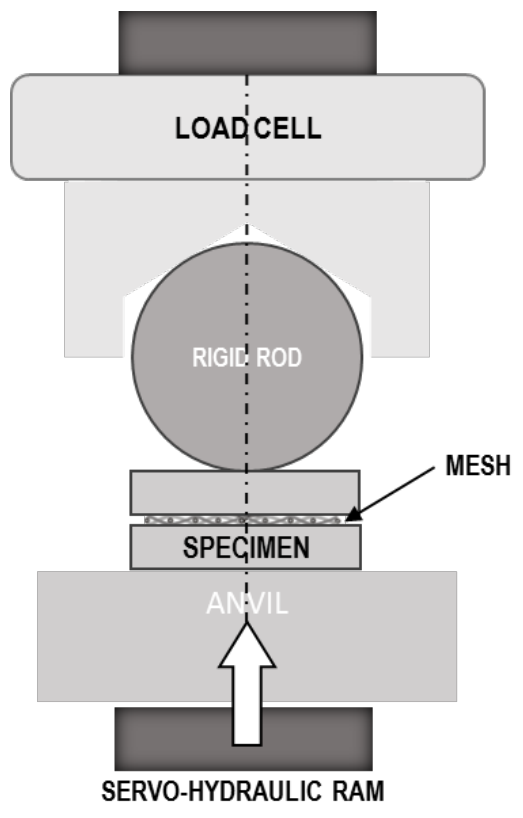

(a)

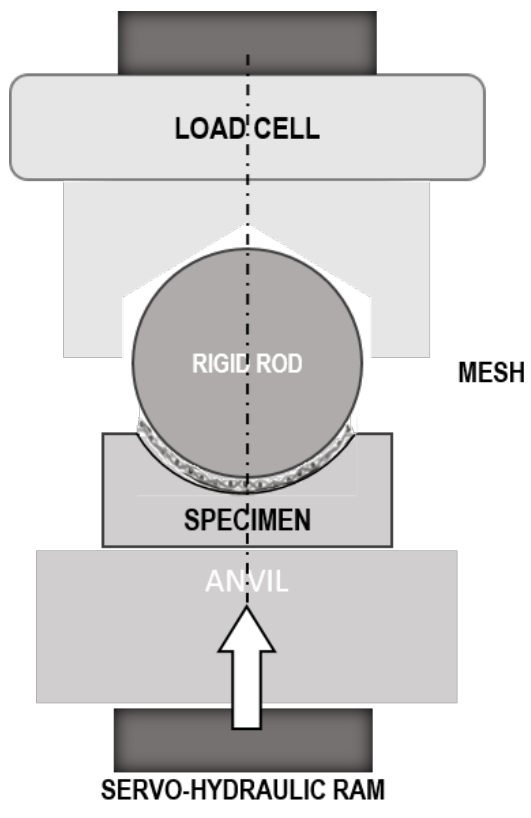

(b)

Figure 11. Two methods of CTx on bronze specimen for later DLC coatings. (a) A cylindrical carbide bar pressing a wire mesh into a flat bronze coupon through a top steel coupon. (b) A cylindrical bar pressing the wire mesh into a machined curved bronze whose curvature matched that of rotating steel specimen in VLBT friction tests.
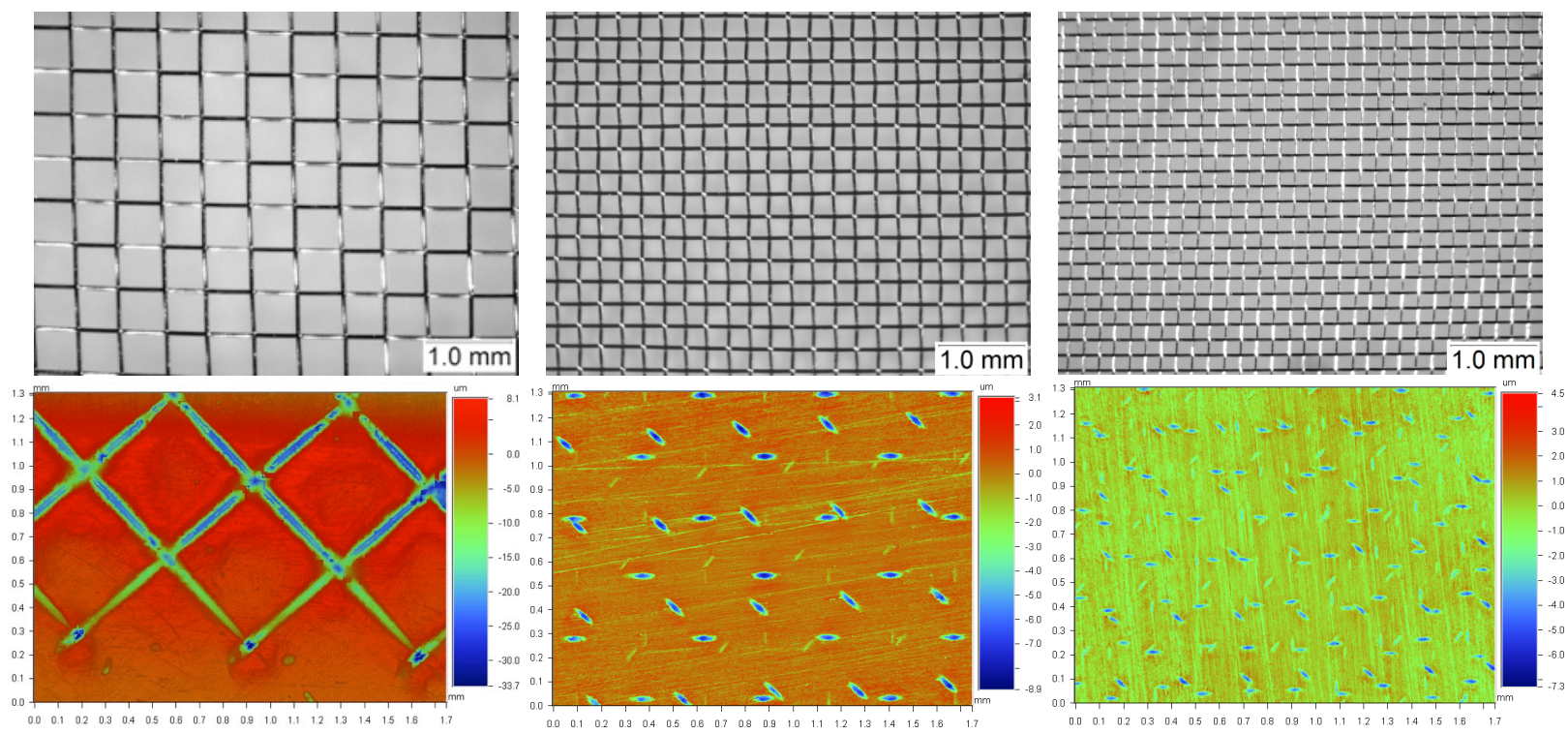

Figure 12. Top (left-to-right): Tungsten wire meshes of 50x50 (0.002" wire dia.), 100x 100 (0.001" wire dia.), and 140x140 (0.0007" wire dia.); Bottom (left-to-right): surface textures created by the 50x50, 100x100, and 140x140 meshes, respectively.

The left chart in Figure 13 shows the load-displacement history of an experiment like that shown in Fig. 12 (b). The load-displacement record clearly shows engagement, strip bending, and indentation that occurs when the strip is bottomed out into the die. The right image in Figure 13 is a curved strip of CDA 260 brass formed with a textured pattern produced by CTx-50. 

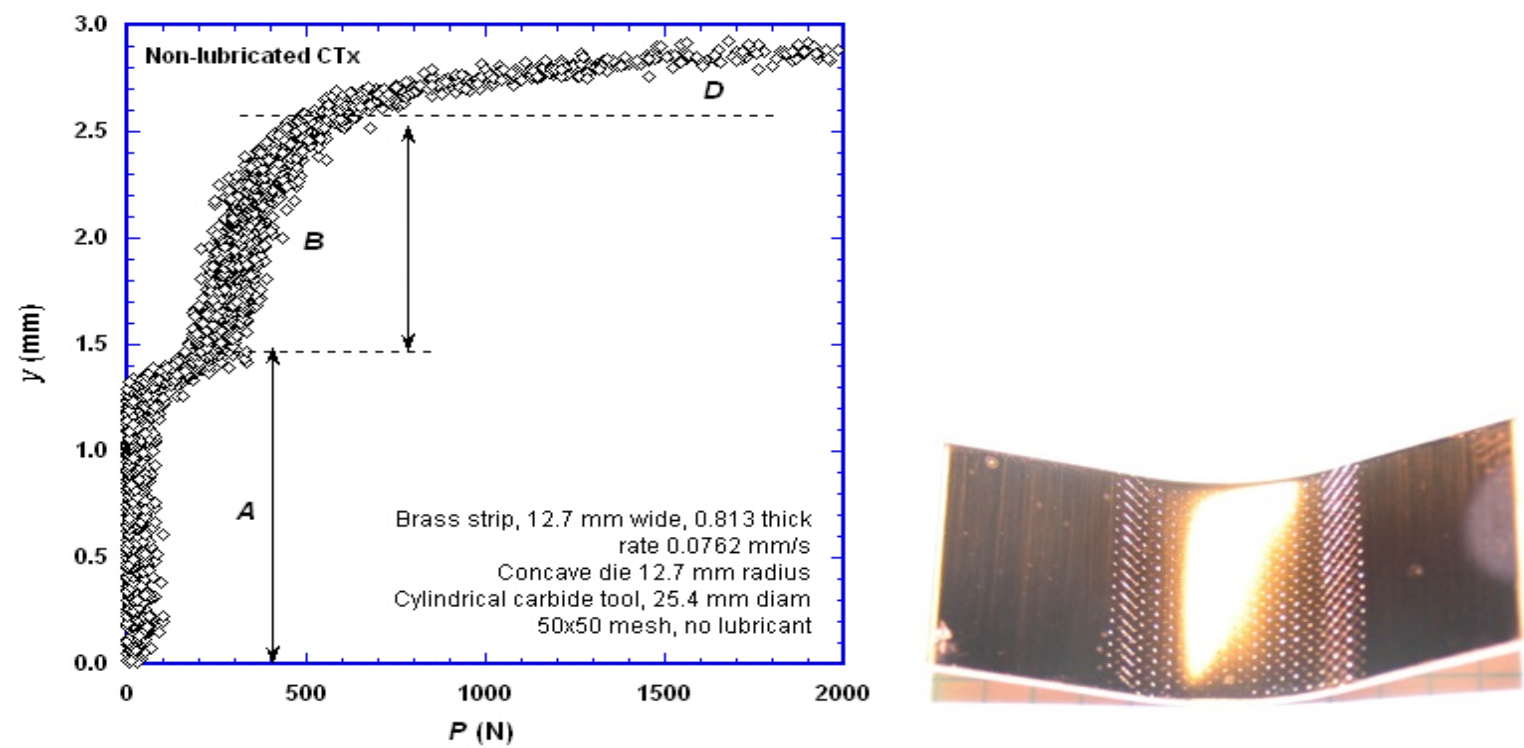

Figure 13. Left: Features of a conformal bend WCTx process. Ram approach (A), bending (B), and an indentation portion (D) of the experiment can be observed. Right: Curved strip of CDA 260 brass formed with a textured pattern on the load bearing surface.

\section{Friction and wear of WCTx specimens}

The CTx-surface delivered promising results. In a conformal contact, the fine CTx (50x50) on curved strips of brass reduced the friction by $20-40 \%$ in SAE $15 \mathrm{~W}-40$ and $0 \mathrm{~W}-30$ engine oils, as shown in Fig. 14. In contrast, the coarse CTx $(20 \times 20)$ actually increased the friction.
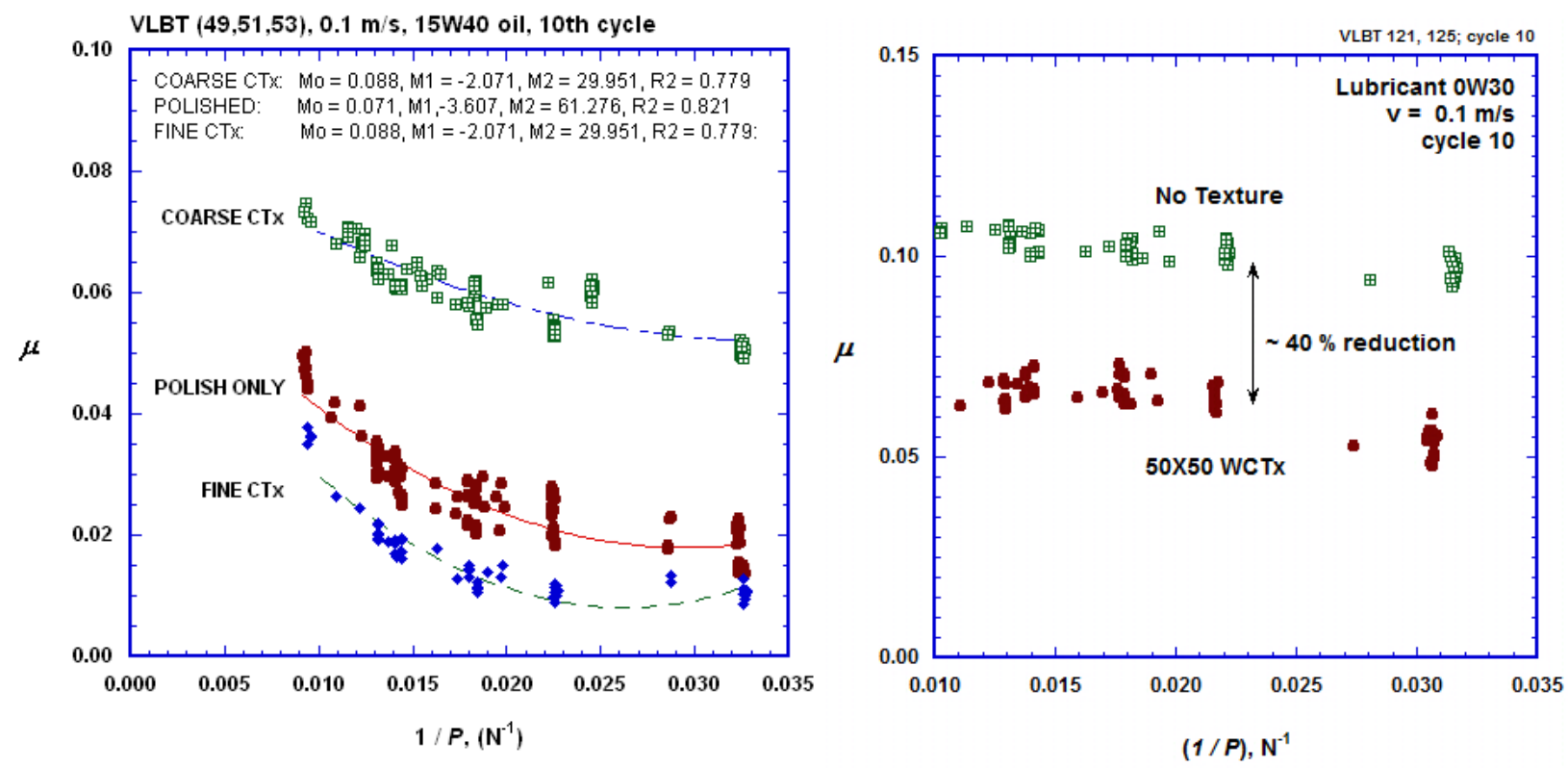

Figure 14. ORNL CTX-surface demonstrated a friction reduction of $20-40 \%$. 
Three methods in creating textures on bronze bearing surfaces have been developed and evaluated at ORNL, as summarized in Table 1. The micro- and ball- indentation arrays are no longer in focus because of their non-favorable results in friction behavior and limitation in scale production. The wire mesh compression has been identified as a feasible texturing process for bronze surfaces, with $20-40 \%$ friction reduction as demonstrated in bench tests.

Table 1. Summary of methods used at ORNL in producing surface textures on bronze bearings.

\begin{tabular}{|l|l|l|}
\hline Method & $\begin{array}{l}\text { Observations } \\
\text { Micro-indentation array }\end{array}$ & $\begin{array}{l}\text { Friction results not encouraging } \\
\text { - edge issues, area fraction too } \\
\text { small, and depth-area ratio too } \\
\text { high. (time consuming) }\end{array}$ \\
work
\end{tabular}

\section{Select wear-resistant thin coatings for CTx surfaces}

Although textures have shown promising results in friction reduction, as shown in Fig. 14, wear, and sometimes scuffing failure, is inevitable for the relatively soft bronze surface in mixed and boundary lubrication. The approach to address the wear issue was application of a wear-resistant coating to preserve the texture. Based on literature search, three coatings were considered as candidates: electroless $\mathrm{Ni}$ plating, CrN by sputtering, and diamond-like-carbon (DLC) by physical vapor deposition. The Ni plating failed in the initial trial and the sputtering system is not fully functional. On the other hand, a reliable commercial supplier of DLC coatings was identified: Northeast Coating Technologies (NCT). A NCT hydrogenated DLC coating (a-C:H) exhibited strong binding to the metal substrate and excellent wear resistance. Therefore, the NCT DLC coating was selected and deposited onto the wire compressiontextured CTx bronze surfaces, as shown in Figure 15. Before coating, the CTx bronze samples were carefully polished by 600 grit sandpaper to remove the pile-ups from the compression. Figure 16 shows the topographical 3D images of DLC-coated CTx-100 surface and CTx-140 surface. 


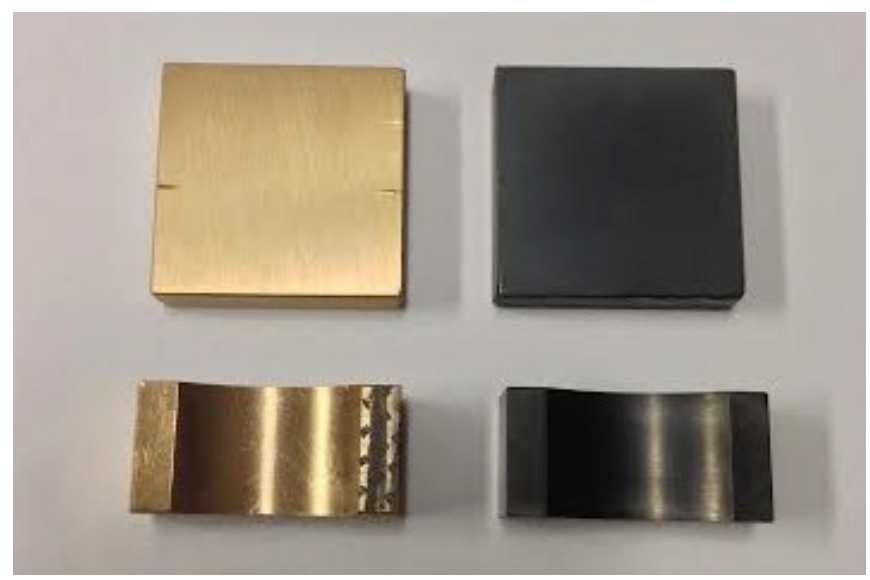

Figure 15. Bronze substrate and DLC coated surfaces in both flat and curve forms (both in 1" wide).

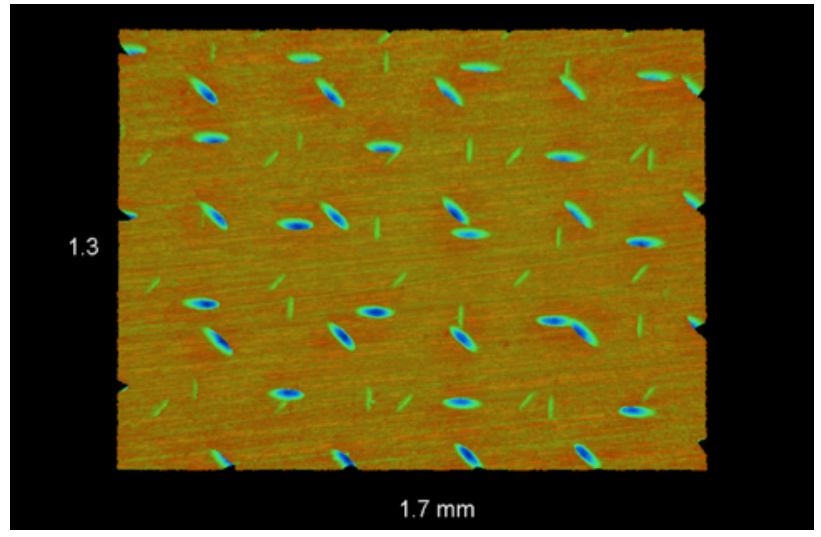

(a)

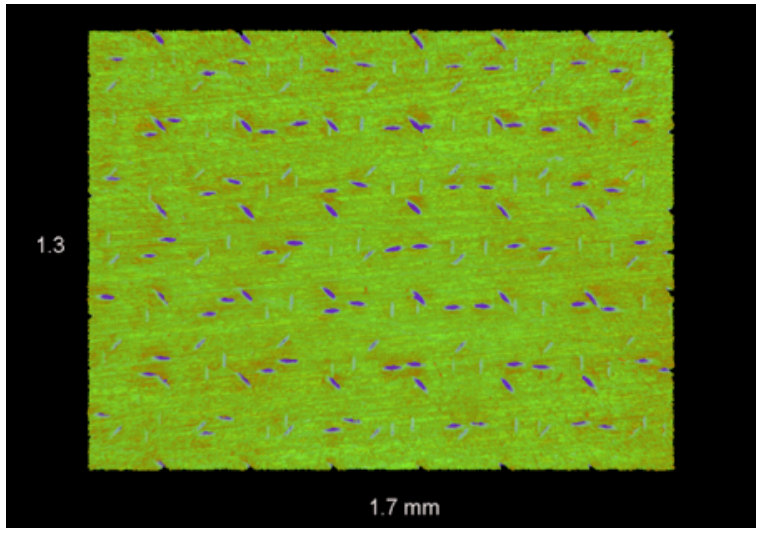

(b)

Figure 16. 3D interferometry profiles of DLC-coated (a) CTx-100 surface (b) CTx-140 surface.

\section{Friction and wear of DLC coated CTx specimens}

Friction and wear reductions were observed in bench testing. Figure 3a compares the friction behavior of uncoated bronze surfaces against a CTx+DLC surface in a SAE 0W-30 engine oil. Tests were conducted using a Stribeck curve scan under a constant load of $20 \mathrm{~N}$ and various sliding speed from 0.5 to $0.05 \mathrm{~m} / \mathrm{s}$. Poor repeatability was seen on uncoated bronze due to wear (see Fig. 3b). In contrast, consistently lower friction was observed for the DLC-coated textured surface (Fig. 3a) with no measurable wear (Fig. 3c). 
(a)

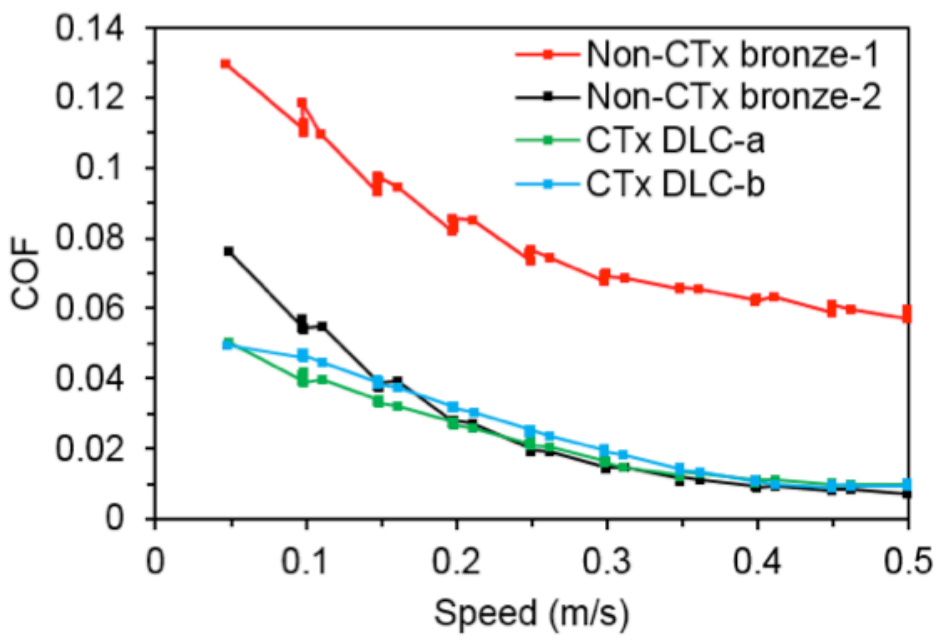

(b)

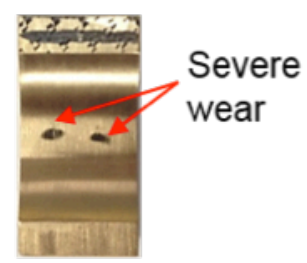

(c)

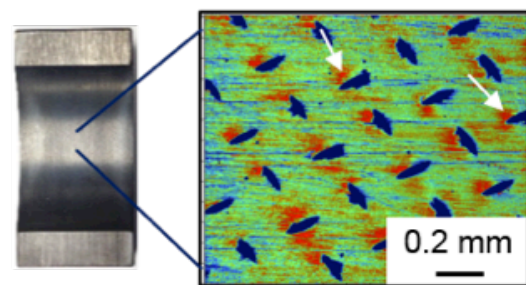

Non-CTx bronze

CTX DLC

Figure 17. (a) Friction behavior of CTx DLC and non-CTx bronze curved surfaces; (b) post-testing image shows worn spots on uncoated bronze; (c) no detectable wear on DLC-coated surface and the texture was well preserved.

Table 2 summarizes the test matrix and key observations for the non-textured, textured, coated, and textured+coated surfaces against a steel counterface in a low-viscosity SAE 0W-30 engine oil. Stribeck curve friction tests were carried out on the Variable Load/Speed Bearing Tester (VLBT) as well as a Pinon-Disc (POD) system under a series of loads and speeds. All VLBT tests were carried out under a $100 \mathrm{~N}$ load and all POD tests were conducted at $10 \mathrm{~N}$. In any case, the DLC coating exhibited strong binding to the substrate and excellent wear resistance.

Friction results are shown in Figure 18. The effects of surface textures are highly dependent on the test configuration and parameters, and could be either beneficial (micro-elastohydrodynamic lift) or detrimental (higher effective roughness) on friction behavior. 
Table 2. Text matrix and key observations.

\begin{tabular}{|c|c|c|c|}
\hline Tribometer & Configuration & Sample surface & Notes \\
\hline \multirow[t]{2}{*}{ VLBT } & $\begin{array}{l}\text { Cylinder } \\
\text { (steel)-on-flat } \\
\text { (sample) }\end{array}$ & $\begin{array}{l}\text { Non-CTx bronze } \\
\text { CTx } 100 \text { bronze } \\
\text { Non-CTx DLC } \\
\text { CTx } 100 / 140 \text { DLC }\end{array}$ & $\begin{array}{l}\text { DLC surface effectively protected the CTx texture, } \\
\text { but the friction benefits were hardly observed due } \\
\text { to the relatively small contact area. Selected } \\
\text { results are shown in Fig. 18a. }\end{array}$ \\
\hline & $\begin{array}{l}\text { Cylinder } \\
\text { (steel)-on- } \\
\text { curved } \\
\text { (sample) }\end{array}$ & $\begin{array}{l}\text { Non-CTx bronze } \\
\text { CTx } 100 \text { DLC }\end{array}$ & $\begin{array}{l}\text { The most successful test configuration with } \\
\text { significant friction and wear reduction } \\
\text { demonstrated on the DLC-coated CTx-textured } \\
\text { surface. See results in Fig. 18b. (Drawback: } \\
\text { samples somewhat difficult to make.) }\end{array}$ \\
\hline \multirow[t]{3}{*}{ POD } & $\begin{array}{l}\text { Ring (sample)- } \\
\text { on-disc (steel) }\end{array}$ & $\begin{array}{l}\text { Non-CTx DLC } \\
\text { CTx } 100 \text { DLC }\end{array}$ & $\begin{array}{l}\text { Friction could be quantified because the current } \\
\text { load cell is not sensitive enough. }\end{array}$ \\
\hline & $\begin{array}{l}\text { Flat pin (steel)- } \\
\text { on-disc } \\
\text { (sample) }\end{array}$ & $\begin{array}{l}\text { Non-CTx bronze } \\
\text { CTx } 100 / 140 \\
\text { bronze } \\
\text { Non-CTx DLC } \\
\text { CTx } 100 / 140 \text { DLC }\end{array}$ & $\begin{array}{l}\text { Since the dimples were in intermittent contact, no } \\
\text { sustainable local EHD lift was generated, thus no } \\
\text { friction reduction. The rougher CTx surfaces in } \\
\text { fact increased the friction due to higher roughness } \\
\text { (Fig. 18c). }\end{array}$ \\
\hline & $\begin{array}{l}\text { Flat pin } \\
\text { (sample)-on- } \\
\text { disc (steel) }\end{array}$ & $\begin{array}{l}\text { Non-CTx DLC } \\
\text { CTx } 100 \text { DLC }\end{array}$ & $\begin{array}{l}\text { The trial of switching the counterparts in POD was } \\
\text { not successful. Unwanted vibration led to high } \\
\text { friction in the entire range of testing speeds (Fig. } \\
18 \mathrm{~d} \text { ). }\end{array}$ \\
\hline
\end{tabular}

(a)

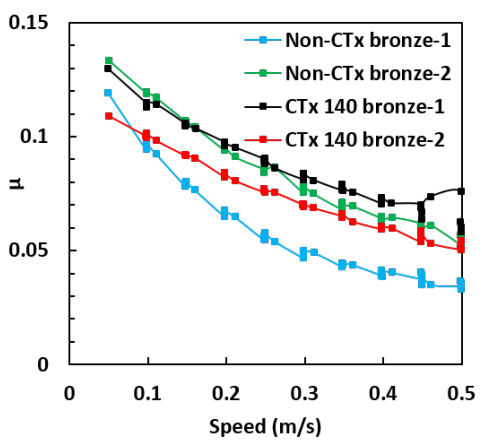

(c)

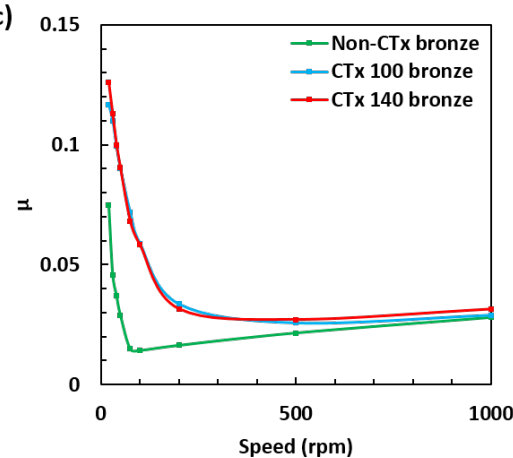

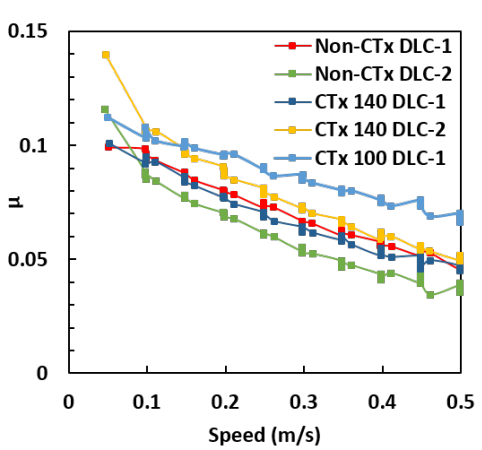
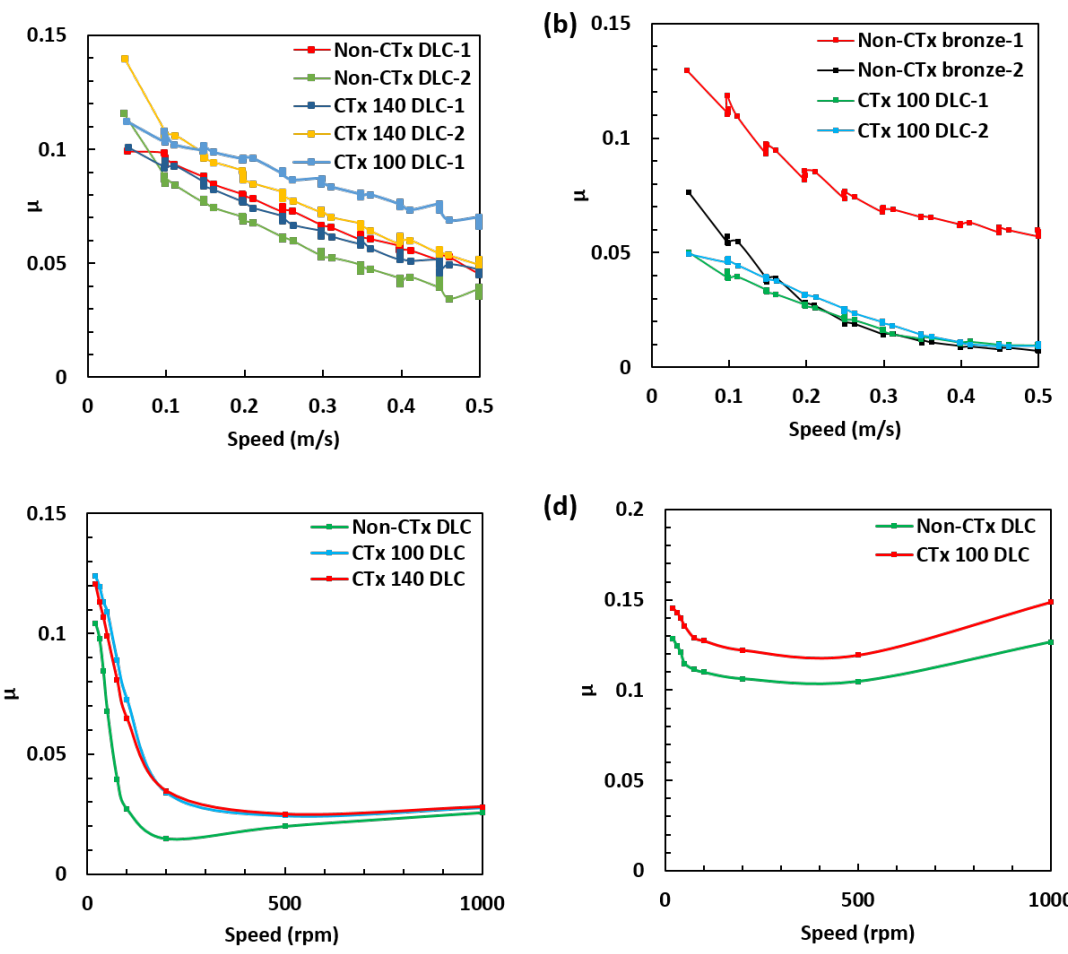

(d)

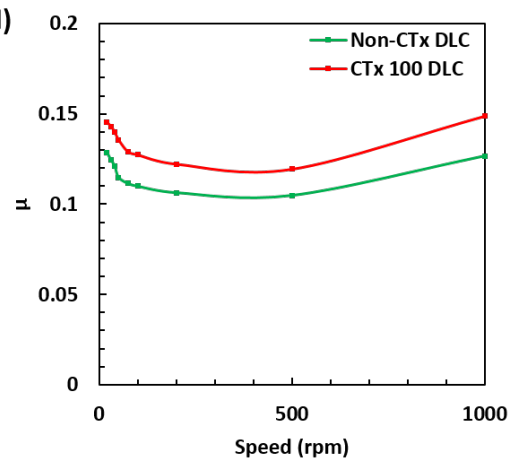

Figure 18. Stribeck friction curves generated in tests of (a) VLBT cylinder (steel)-on-flat (sample), (b) VLBT cylinder (steel)-on-curved (sample), (c) POD flat pin (steel)-on-disc (sample), and (d) Flat pin (sample)-on-disc (steel). 


\subsection{Photolithographic Texturing (GWU)}

The basic principles of surface texture design are summarized as follows: (1) hydrodynamic lubrication regime - the friction reduction with surface texturing has been demonstrated in both bench tests and limited industrial applications. The effects of textured surfaces are a) enhanced hydrodynamic lubrication with dimples or grooves; b) possible cavitation effect; and c) reverse flow induced by dimples or grooves [9]. (2) elastohydrodynamic lubrication regime - both numerical modeling and experimental results indicated that the dimple edge angle, bottom shape and dimple spacing are important, and potential cavitation lift could be one of the mechanisms to the effect of friction reduction; (3) boundary lubrication regime - the squeeze of lubricant can provide extra lift, and meanwhile, contact mechanics becomes important that the edge stress of dimple could reach the level that equivalent to asperity contact. An integrated design with multi-scale surface texture needs to be achieved for components operated in multiple lubrication regimes. The parameters considered for surface texture design are the shape and aspect ratios of dimples, dimple depth, dimple arrangements and spacing, as well as density of dimples.

One of the challenges facing those who texture surfaces is translating those techniques into practice, a laboratory procedure that can texture flat test strips is not practical for curved surfaces like those on piston rings, cylinder liners, cams, and bearing inserts. One of GWU's principle accomplishments in this project was to develop a soft masking technique that enabled patterns to be placed on curved surfaces. That process is shown in Figure 19. The textured surface was slid against a $1.2 \mathrm{~cm}$ wide counterface cut from a cast iron cylinder liner, a shown at the right of the figure. The sliding direction for friction tests was in and out of the plane of the figure.

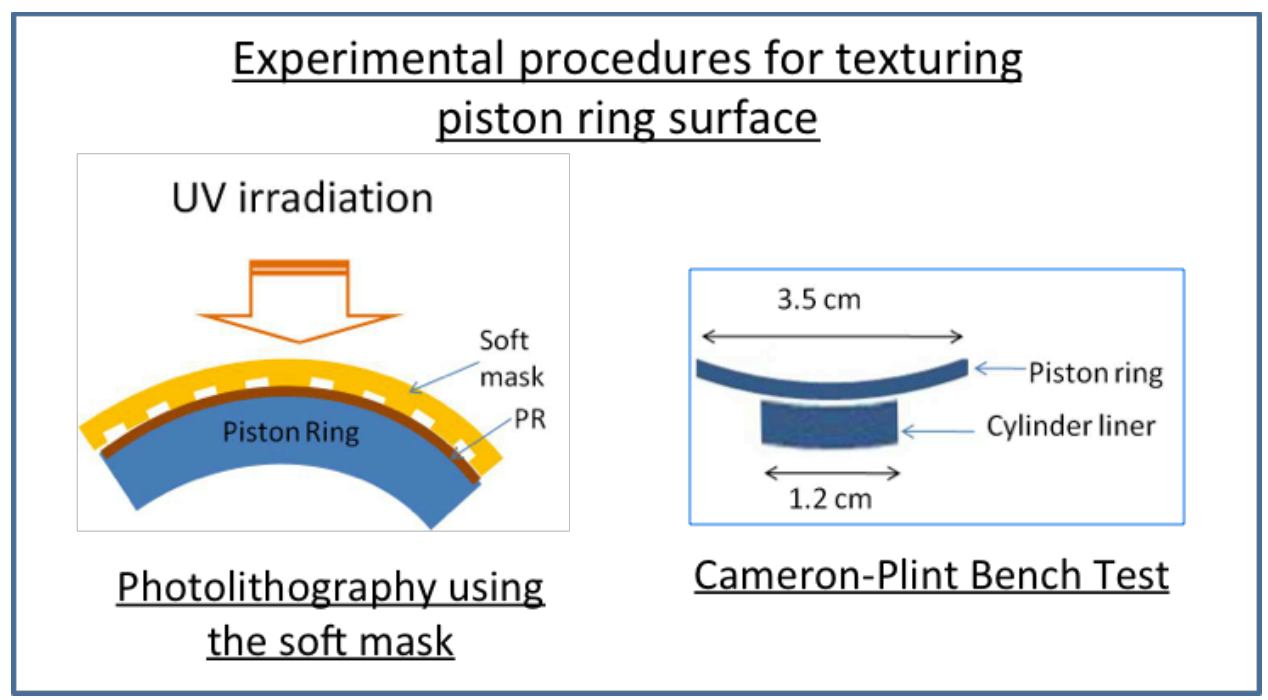

Figure 19. Process for producing a texture on a curved surface by photolithography. $U V=$ ultraviolet, $P R=$ photoresist. (GWU diagram).

\subsection{Texturing of Piston Rings}

Textured surfaces were placed on several types of piston rings. Some ring segments were supplied by ORNL and were from the same batch used in the interlaboratory testing program during development of ASTM Standard G181 [10]. Flat surfaced rings were obtained by GWU from a different diesel engine maker. Apparently, the rings used for the ASTM work were designed to have pits and irregular features. 
This finish may be the result of a form of a carefully designed chemical compositional texture to prevent seizure by creating oil reservoirs on the ring surface (see Fig. $20 \mathrm{a}, \mathrm{b}$ ). With such a starting surface, the outcomes of texturing could not be predicted, and a decision was made to purchase a different batch of piston rings that had a flat ring interface design.

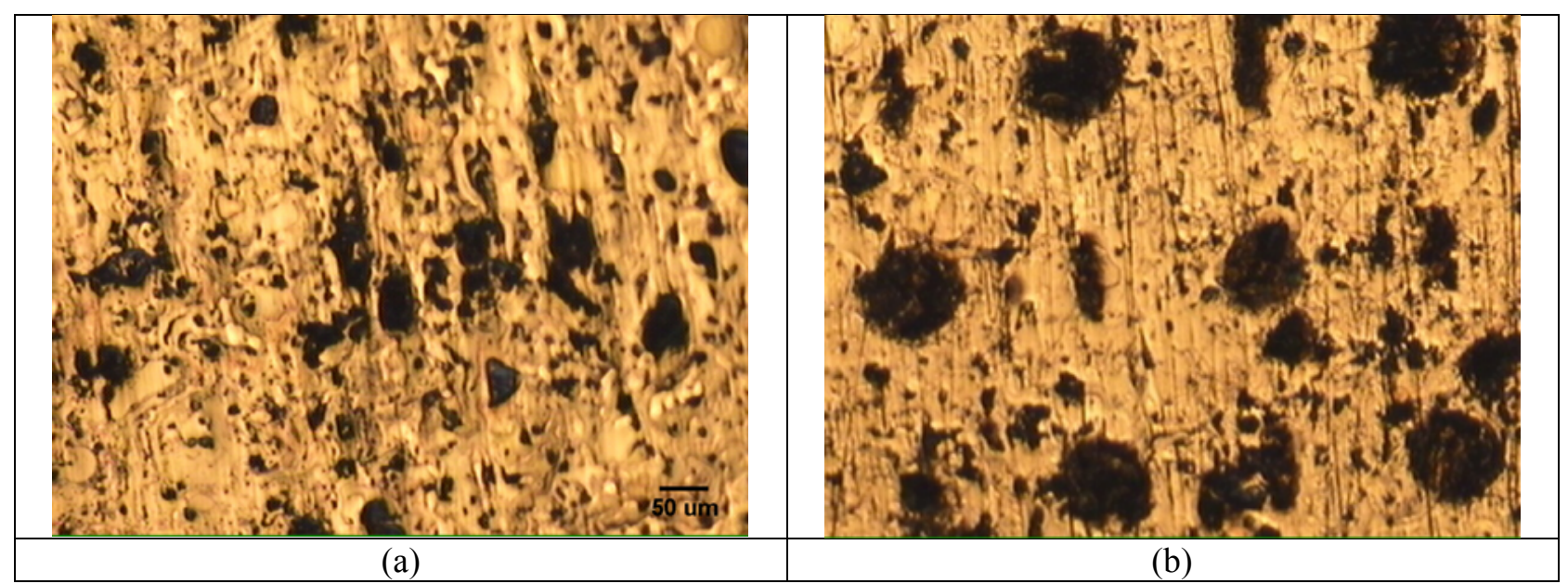

Figure 20. Surface of a commercial heavy duty diesel top piston ring showing (a) inherent porosity, and (b) posttextured surface illustrating the difficulty of distinguishing the texture patterns from the pre-existing porosity.

Circles are approximately $70 \mu \mathrm{m}$ in diameter. (GWU photomicrograph).

Reciprocating friction tests in stabilized mineral oil clearly showed that the mixture of circles and ellipses produced the best friction reduction, compared with either shape individually (see Figure 21). Small bumps in the curve were produced as the load was changed during the test.

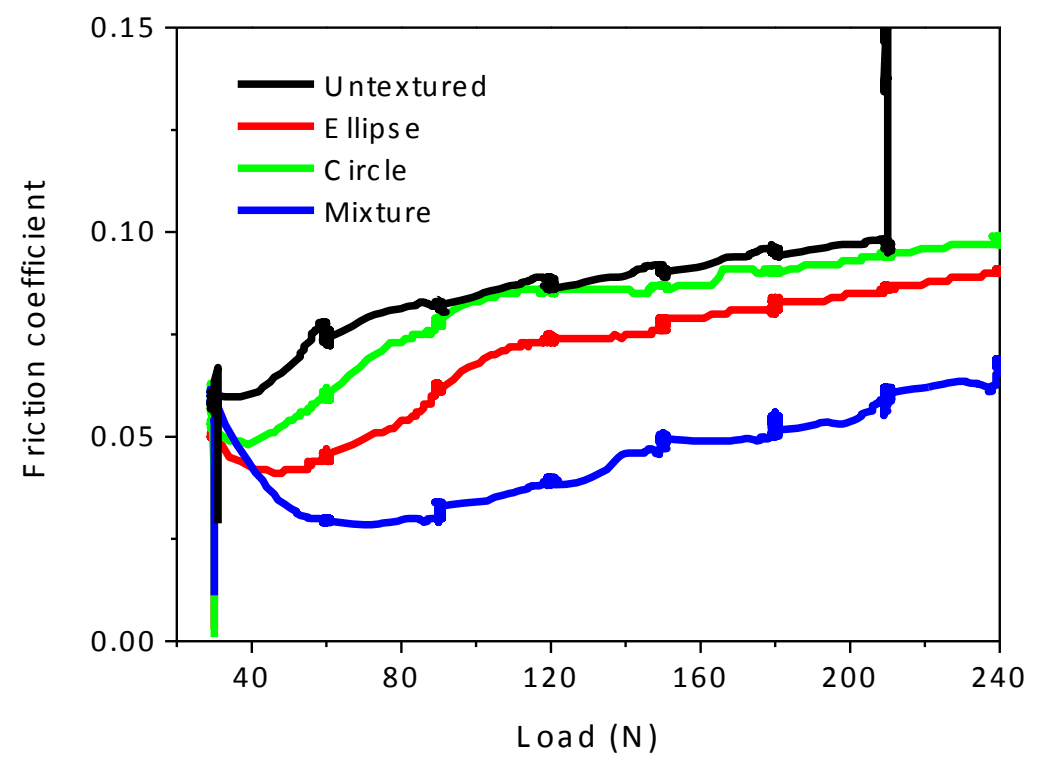

Figure 21. Effects of texture pattern feature shape on friction reduction under lubricated conditions. (GWU data)

The same data shown in Fig. 21 can be plotted as a function of the typical horizontal axis parameter used in Martens-Stribeck curves which are familiar to bearing designers (see Fig. 22). That dimensionless 
parameter is $(\eta v L / W)$ where $\eta=$ kinematic viscosity, $v=$ sliding velocity, $L=$ bearing length and $W=$ load. The non-textured specimen failed by scuffing at a load of $210 \mathrm{~N}$.

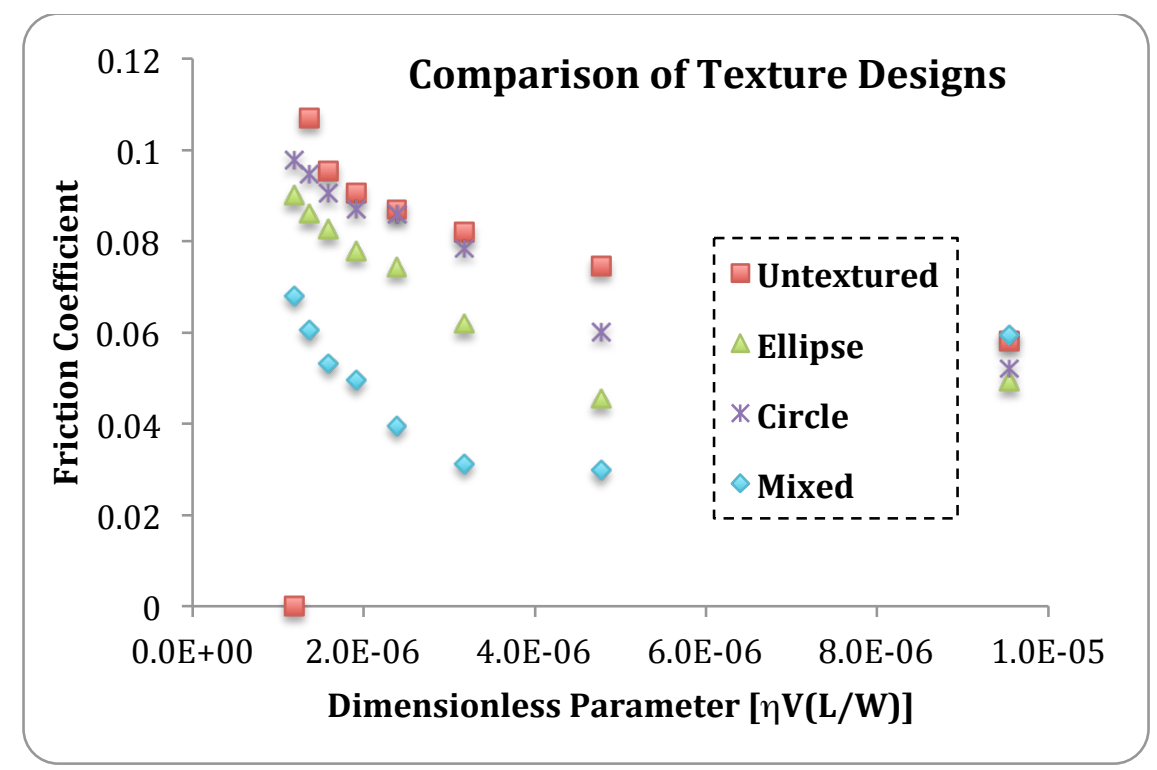

Figure 22. Minimum in friction corresponding to various textured and non-textured rings Conditions: lubricated with a white oil (ISO 30 grade containing 2\% Tricresylphosphate (TCP) and 1\% antioxidant). Stroke length was $12.4 \mathrm{~mm}$ and frequency of oscillation was $24 \mathrm{~Hz}$. (GWU data)

\subsection{Texturing of Simulated Cam Surfaces}

For testing the surface texture designs, actual cam roller follower contact is difficult to simulate. There had been expensive testers using actual components such as the MIRA test and motored engine test, but the precision of the test is poor. So in this study, we decided on using simulation models to calculate the interfacial properties of the cam roller contact and then use a ring on block tester (low contact stress) and a ball-on-three-flats configuration of a four ball wear tester (high contact stress) for the study.

Ring on block test: Two types of simple texture designs were selected: one with elliptical shape dimples and the other with circular shape dimples. Soft mask and photolithography technique was used and followed with electro-chemical etching to fabricate the textures on pre-worn block specimens. Same test procedure as described in the previous section was used for Block-on-Ring testing with textured specimens. The comparison friction measurement results at various speeds of 100 and $600 \mathrm{rpm}$ are shown in Figure 23. As expected, the texture design with circular shape dimples has higher friction coefficient than that of baseline. However, the texture design with elliptical shape dimples demonstrated friction reduction in all speeds and applied loads tested. Compared to the baseline results, the overall friction reduction of ellipse texture design is in the range of $12-20 \%$. Significant friction reduction of ellipse texture design is observed up to $85 \%$ at low load, high speed condition. 

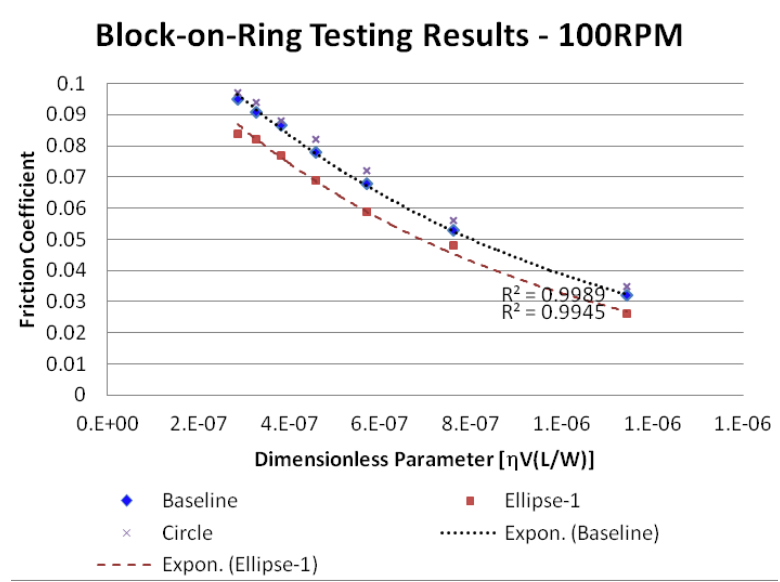

\section{Block-on-Ring Testing Results - 600RPM}

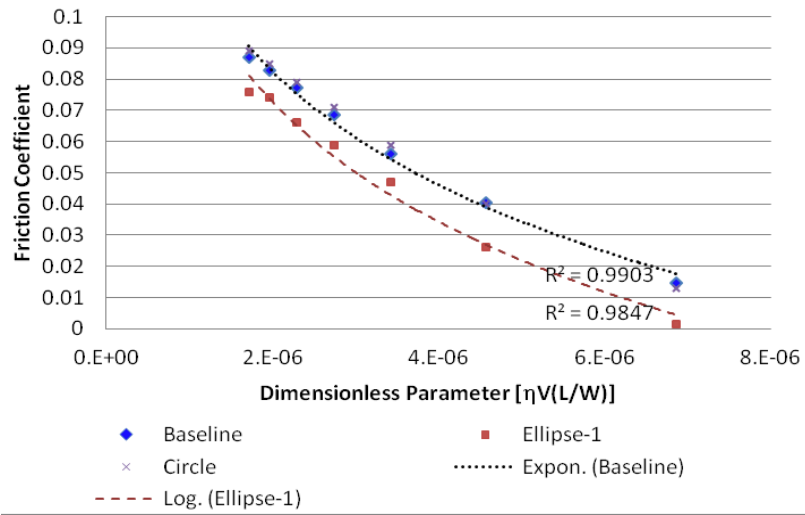

Figure 23. Friction coefficient comparison of surface texture at various speeds (non- textured block as baseline; texture design of ellipse and circle).

Ball-on-three-flats test: The ring on block tester has the right contact geometry but the contact stress level is much lower than the engine components involved. Therefore, we also used the ball on three flats contact geometry in a modified four ball tester, which is capable of much higher load and speed than the commercial four ball machines. Pure paraffin white oil with $1 \mathrm{wt}$. \% Tricresyl phosphate and $2 \mathrm{wt} . \%$ antioxidant was used as the lubricant and disks without texturing were used for baseline comparison. Friction coefficients of all the nine textures are summarized in Figure 24. As can be seen, the circular textures show better friction-reducing performance under low load and high speed circumstances $(5 \mathrm{~kg}$ and $1.15 \mathrm{~m} / \mathrm{s}$ ), especially for textures with mixed circles (C-2 and C-3). The friction coefficient was reduced from 0.53 for untextured disks to 0.34 for the C-3 texture. Under high load conditions, however, the friction coefficient is generally higher than those of other textures or even the baseline. In contrast, the elliptical textures display obvious friction-reducing effect during the whole test procedure, especially under the severe high load and low speed conditions (e.g., $25 \mathrm{~kg}$ and $0.38 \mathrm{~m} / \mathrm{s}$ ). The textures of mixed circles and ellipses present better friction-reducing performance than the other two kinds of textures under medium load and speed conditions (usually between $5-10 \mathrm{~kg}$ and $0.96-0.77 \mathrm{~m} / \mathrm{s}$ ). After a proper combination of different textures on different zones of cam surface, Figure 24, a reduction of friction coefficient by $15-20 \%$ could be expected.

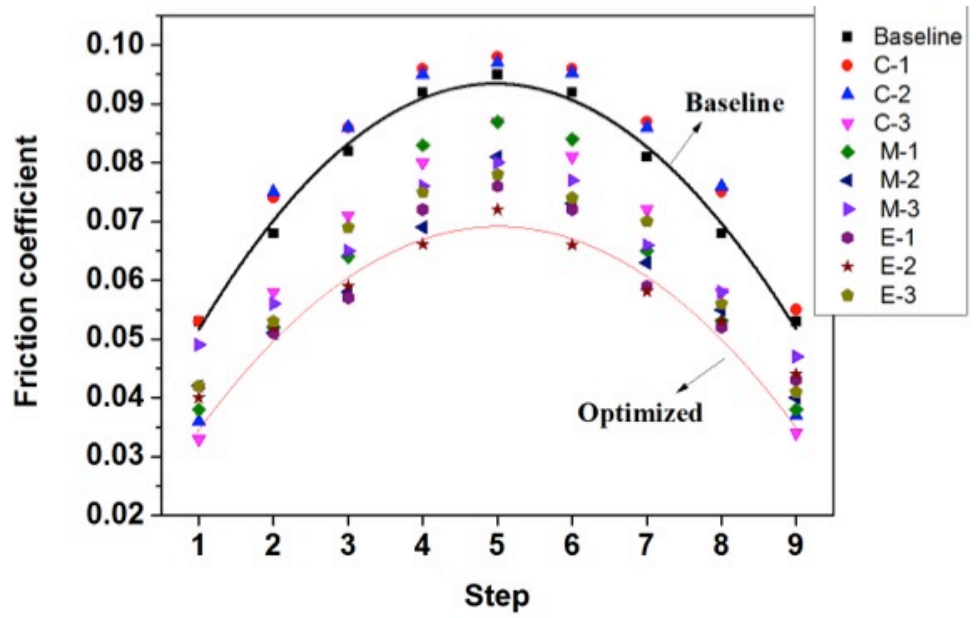

Fig. 24. Summarization of friction coefficients for nine textures. 


\subsection{Conclusions and Recommendations}

The general findings associated with the work conducted at ORNL and GWU in the course of this effort are largely consistent with the conclusions reached in the technology review in Ref [3]; namely, that surface modification by texturing, as a strategy to reduce or control friction in lubricated moving parts, must be selected and applied carefully on a case-by-case basis in order to maximize benefits while avoiding unintended negative effects. Exclusive of cost considerations, the following technical issues must be considered in the design, selection, and application of textures to lubricated surfaces of engine components for friction reduction:

1) Not only the nominal operating parameters, but the range of lubrication regimes experienced by engine components during operation should be considered when selecting a texture. Some kinds of textures seem to work better in full film or mixed lubrication regimes than they do in boundary lubrication regimes.

2) Effects of surface textures are highly dependent on the test configuration and parameters, and could be either beneficial (micro-elastohydrodynamic lift) or detrimental (higher effective roughness) on friction behavior.

3) Mechanical and laser dimpling methods of texturing can leave residual upraised rims near features that need to be removed by polishing or grinding, lest they disrupt the effects of the texture.

4) Texture design need not be limited to a single feature shape, size, or spacing. In fact if the range of operating conditions is wide, then a mixed pattern, like the ovals and circles used in GWU experiments, may provide more benefit than would a single-feature geometry.

5) The density and depth of depressions must be high enough so that their beneficial effects can be utilized. Proximity of features helps to maintain beneficial turbulence that would dissipate over larger spacings. Widely-spaced features and dimple densities below about $15-20 \%$ of the total surface seems not to work very well.

6) The alignment of surfaces is critical to the correct function of designed textures. Misalignment of mating surfaces can disrupt the lubricant film stability needed to realize frictional reductions from texturing.

7) Surfaces with preexisting porosity, like some types of commercial thermally-sprayed piston ring coatings are difficult to texture because the pre-existing pores can disrupt the application of a controlled texture geometry, and such hard coatings can also be difficult to work with in forming textures by techniques like photolithography.

8) Textures must last long enough to realize their benefits. If a pattern is worn off early in component operation, any frictional reduction other than that from normal wear-in would be lost. Treating textures with hard coatings or other hardening treatments would extend their beneficial effects. This work has demonstrated the feasibility of using a wear-resistant DLC coating to protect the compression-produced textures on soft bronze bearing surfaces. 


\section{Acknowledgements}

Research sponsored by the Vehicle Technologies Office, Office of Energy Efficiency and Renewable Energy, U.S. Department of Energy (DOE).

Notice: This report has been authored by UT-Battelle, LLC, under Contract No. DE-AC05-00OR22725 with the U.S. Department of Energy. The United States Government retains and the publisher, by accepting the article for publication, acknowledges that the United States Government retains a nonexclusive, paid-up, irrevocable, world-wide license to publish or reproduce the published form of this manuscript, or allow others to do so, for United States Government purposes.

\section{References}

[1] "Workshop Report: Trucks and Heavy-Duty Vehicles Technical Requirements and Gaps for Lightweight and Propulsion Materials," U.S. Dept. of Energy, Vehicle Technologies Office, February 2013, p. iii.

[2] S.C. Davis, S.W. Diegel, R.G. Boundy, ed. (2011) Transportation Energy Data Book, $30^{\text {th }}$ Edition, Oak Ridge National Laboratiry report ORNL-6986, cta.ornl.gov/data, p. 5-15.

[3] P.J. Blau, "Use of Textured Surfaces to Mitigate Sliding Friction and Wear of Lubricated and NonLubricated Contacts" Technical Report ORNL/TM - 2012/20.

[4] A. Ronen, I. Etsion, Y. Kligerman, "Friction-reducing surface-texturing in reciprocating automotive components," Tribol T 2001, 44 (3), 359-366.

[5] A. Ramesh, W. Akram, S.P, Mishra, A.H. Cannon, A.A. Polycarpou, W.P. King, "Friction characteristics of microtextured surfaces under mixed and hydrodynamic lubrication," Tribology International 2013, 57, 170-176.

[6] H.L. Costa, I.M. Hutchings, "Hydrodynamic lubrication of textured steel surfaces under reciprocating sliding conditions," Tribology International 2007, 40 (8), 1227-1238.

[7] M. Wakuda, Y. Yamauchi, S. Kanzaki, Y. Yasuda, "Effect of surface texturing on friction reduction between ceramic and steel materials under lubricated sliding contact," Wear 2003, 254 (3-4), 356363.

[8] U. Pettersson, S. Jacobson, "Influence of surface texture on boundary lubricated sliding contacts," Tribology International 2003, 36 (11), 857-864.

[9] C.M. Taylor, "Fluid-film Lubrication in the Internal Combustion Engine: An Invited Review", J. Phys. D: Appl. Phys., 25 (1992), A91-A100.

[10] ASTM Standard G181, "Standard Test Method for Conducting Friction Tests of Piston Ring and Cylinder Liner Materials Under Lubricated Conditions," ASTM International Annual Book of Standards, 03.02 (2004). 


\section{Appendix. List of Publications/Presentations}

1. P. J. Blau, Use of Textured Surfaces to Mitigate Sliding Friction and Wear of Lubricated and NonLubricated Contacts, ORNL Tech Report ORNL/TM-2012/20 (2012).

2. N. R. Davies and P. J. Blau, Comparison of Frictional Heating Models, ORNL Tech Report ORNL/TM-2013/398 (2013).

3. P.J. Blau, K.M. Cooley, and D.L. Erdman, "Effects of Indentation and Compression Texturing on the Lubricated Friction of Non-Ferrous Surfaces under Spectrum Loading," STLE $69^{\text {th }}$ Annual Meeting \& Exhibition, Orlando, May 18-22, 2014.

4. P. J. Blau, K. M. Cooley, and Jun Qu, "Friction Reduction Through Surface Modification,” 2014 DOE Vehicle Technologies Program Annual Merit Review, D.C., June 19, 2014. 